\title{
Calibration of Noah Soil Hydraulic Property Parameters Using Surface Soil Moisture from SMOS and Basinwide In Situ Observations ${ }^{\mathfrak{a}}$
}

\author{
Peter J. Shellito And ERIC E. SMAll \\ Department of Geological Sciences, University of Colorado Boulder, Boulder, Colorado \\ Michael H. COSH \\ Hydrology and Remote Sensing Laboratory, Agricultural Research Service, \\ USDA, Beltsville, Maryland
}

(Manuscript received 20 August 2015, in final form 8 June 2016)

\begin{abstract}
Soil hydraulic properties (SHPs) control infiltration and redistribution of moisture in a soil column. The Noah land surface model (LSM) default simulation selects SHPs according to a location's mapped soil texture class. SHPs are instead estimated at seven sites in North America through calibration. A single-objective algorithm minimizes the root-mean-square difference (RMSD) between simulated surface soil moisture and observations from 1) a dense network of in situ probes, 2) Soil Moisture Ocean Salinity (SMOS) satellite retrievals, and 3) SMOS retrievals adjusted such that their mean equals that of the in situ network. Parameters are optimized in 2012 and validated in 2013 against the in situ network. RMSD and unbiased RMSD (ubRMSD) assess resulting surface soil moisture behavior. At all sites, assigning SHP parameters from a different soil texture than the one that is mapped decreases the RMSD by an average of $0.029 \mathrm{~cm}^{3} \mathrm{~cm}^{-3}$. Similar improvements result from calibrating parameters using in situ network data $\left(0.031 \mathrm{~cm}^{3} \mathrm{~cm}^{-3}\right)$. Calibrations using remotely sensed data show comparable success $\left(0.029 \mathrm{~cm}^{3} \mathrm{~cm}^{-3}\right)$ if the SMOS product has no bias. Calibrated simulations are superior to texture-based simulations in their ability to decrease ubRMSD at times of year when the default simulation is worst. Changes to both RMSD and ubRMSD are small when the default simulation is already good. Most calibrated simulations have higher runoff ratios than do texturebased simulations, a change that warrants further evaluation. Overall, parameter selection using SMOS data shows good potential where biases are low.
\end{abstract}

\section{Introduction}

Hydrologic land surface models (LSMs) use soil hydraulic properties (SHPs) to model redistribution and drainage of water. Surface and root-zone soil moisture content affects runoff, base flow, and partitioning of net radiation between ground, sensible, and latent heat fluxes (LHFs; Entekhabi et al. 1996; Betts et al. 1996). Water and energy fluxes are thus dependent on SHPs. Land

Supplemental information related to this paper is available at the Journals Online website: http://dx.doi.org/10.1175/ JHM-D-15-0153.s1.

Corresponding author address: Peter J. Shellito, Department of Geological Sciences, University of Colorado Boulder, UCB 399, Boulder, CO 80309-0399.

E-mail: peter.shellito@colorado.edu surface parameterizations and soil properties in particular have been shown to significantly affect continentalscale climate simulations (Pitman 2003; Richter et al. 2004; Osborne et al. 2004; Guillod et al. 2013).

SHPs in LSMs are typically assigned using laboratoryderived lookup tables or empirical functions, both based on mapped soil texture (Teuling et al. 2009). This approach is problematic because soil texture is a poor predictor of SHPs (Gutmann and Small 2005, 2007). The existence of soil texture maps allows the practice to persist despite overwhelming evidence that it is ill suited. First, mapped texture classes often do not match the texture observed at the site. Xia et al. (2015) show that correcting for such mismatches does not categorically improve the root-mean-square difference (RMSD) between simulations and in situ observations. Values for both range from 0.03 to $0.09 \mathrm{~cm}^{3} \mathrm{~cm}^{-3}$. Second, models use the mean SHP values of each texture class, but 
commonly used soil databases [including Holtan et al. (1968), Rawls et al. (1976), and Schaap and Leij (1998)] exhibit more SHP variation within a single texture class than between the 12-class means (Gutmann and Small 2005, 2007; Harrison et al. 2012; Soet and Stricker 2003). This indicates an arbitrary discretization of SHPs and a decrease in soil property diversity, which decreases the likelihood of accurate soil properties (Wösten et al. 1995). Third, the scale of LSMs (typically $1-50 \mathrm{~km}$ ) is incommensurate with that of the laboratory $(\sim 10 \mathrm{~cm})$. Soil properties are different when measured at a large scale because they must account for smaller-scale heterogeneities (Grayson and Blöschl 2000; Harter and Hopmans 2004). Fourth, soil structure, organic material, bulk density, and preferential flow through macropores influence soil drainage but are not captured by the typical assignation of sand/silt/clay percentages or texture class (Beven and Germann 1982; Soet and Stricker 2003; Gutmann and Small 2005, 2007). And finally, although use of the Richards equation at field and watershed scales is common, it is not based on sound physical basis; models at the kilometer scale only provide effective representations of unsaturated flow processes (Vereecken et al. 2007; Beven 1995). These problems make small-scale information about soils and hydraulic parameters nearly impossible to use in real-world upscaling approaches (Vereecken et al. 2007). The limitations of such "bottom up" approaches have led to instead using calibration to select parameters. This "top down" strategy does not depend on knowledge of soil classes within the model domain (Ines and Mohanty 2009).

The calibration process matches modeled outputs to observations of those fluxes or states by adjusting model parameters, and it has been shown to improve model performance (Franks and Beven 1997; Gupta et al. 1999; Gutmann and Small 2010; Hogue et al. 2006; Harrison et al. 2012). Studies to date have used runoff, soil temperature, and heat fluxes to calibrate hydrologic model parameters (Sorooshian et al. 1993; Yapo et al. 1996; Franks and Beven 1997; Crow et al. 2003; Liu et al. 2005; Hogue et al. 2005; Nandagiri 2007; Gutmann and Small 2007, 2010).

With a given model and observation set, calibration schemes differ in the number of included parameters. Studies such as Gutmann and Small (2010), Burke et al. (1998), and Santanello et al. (2007) estimate only two to five parameters, which allows them to evaluate the role of each on the observed response. Gupta et al. (1999), Houser et al. (2001), and others, on the other hand, allow for complex interactions between parameters by simultaneously calibrating a dozen or more. Bastidas et al. (2006), however, find overparameterization in complex models, which decreases parameter identifiability. To this point, Beven (1989) points specifically to "making use of measured internal state variables" such as soil moisture as a path toward reducing "equifinality," that is, that different parameter sets can produce equally good simulations (Beven and Binley 1992).

Soil moisture observations are particularly well suited for LSM calibration, as they capture a key component of hydrologic behavior. Because of data availability, past calibration experiments have only utilized soil moisture observations in a small domain or in combination with other data (e.g., Mattikalli et al. 1998; Wooldridge et al. 2003; Koren et al. 2008; Pauwels et al. 2009; Ines and Mohanty 2009; Milzow et al. 2011; Harrison et al. 2012). The present work calibrates a hydrologic model to two large-scale observations of near-surface soil moisture: 1) basin-averaged in situ measurements and 2) remotely sensed observations from the European Space Agency (ESA) Soil Moisture Ocean Salinity (SMOS) satellite mission. Multiyear data are available for both. Because soil moisture alone has never been used to calibrate a model at this temporal and spatial scale, we limit our study to only four parameters that directly affect soil moisture. This is the logical first step before expanding to secondary parameters and interactions. We address the following questions: 1 ) what aspects of modeled soil moisture can be improved through calibration of SHPs with soil moisture and 2) what are the strengths and weaknesses of using SMOS in such calibrations? To assess model calibration success, we investigate the resulting absolute soil moisture values and soil moisture anomalies. Absolute values affect the magnitude of other model fluxes such as LHF and runoff (Betts et al. 1996; Entekhabi et al. 1996). Soil moisture anomalies are useful for characterizing system dynamics (e.g., Kurc and Small 2004) and for assimilation efforts (e.g., Reichle and Koster 2004; Crow et al. 2010; Juglea et al. 2010; Pan et al. 2012; Blankenship et al. 2014).

\section{Methods}

The model setup mimics that of the Noah LSM (Chen and Dudhia 2001; Ek et al. 2003) in phase 2 of the North American Land Data Assimilation System (NLDAS-2; Xia et al. 2012). This framework allows our results to be directly applicable to ongoing NLDAS and NLDAStype research. The calibration process uses observations that are roughly commensurate with the $1 / 8^{\circ}\left(\sim 144 \mathrm{~km}^{2}\right)$ NLDAS resolution, so soil moisture scaling is not part of this study.

\section{a. Model, parameters, and forcing data}

We employ the widely used Noah LSM, version 3.3 (Chen and Dudhia 2001; Ek et al. 2003). Noah is run in a 
TABLE 1. SHP parameters, the limits of their uniform prior distributions, and the ranges of their texture-based default values.

\begin{tabular}{|c|c|c|c|c|c|c|}
\hline \multicolumn{3}{|c|}{ Parameter } & \multicolumn{2}{|c|}{ Uniform prior distribution } & \multicolumn{2}{|c|}{ Noah default values } \\
\hline Name & Symbol & Units & Min & Max & Min & Max \\
\hline Pore size distribution index & $b$ & - & 0.34 & 50.91 & 2.79 & 11.55 \\
\hline Saturated soil moisture content & $\theta_{\text {sat }}$ & $\mathrm{cm}^{3} \mathrm{~cm}^{-3}$ & 0.12 & 0.698 & 0.339 & 0.476 \\
\hline Saturated matric potential & $\psi_{\text {sat }}$ & $\mathrm{m} \mathrm{H}_{2} \mathrm{O}$ & 0.036 & 4.01 & 0.036 & 0.759 \\
\hline Saturated hydraulic conductivity & $K_{\text {sat }}$ & $\mathrm{ms}^{-1}$ & $9.74 \times 10^{-7}$ & $1.51 \times 10^{-4}$ & $9.74 \times 10^{-7}$ & $4.66 \times 10^{-5}$ \\
\hline
\end{tabular}

stand-alone configuration, although it can be coupled directly to an atmospheric model (Skamarock et al. 2008). The soil thickness is set to the default $2 \mathrm{~m}$, with layer boundaries at $10,40,100$, and $200 \mathrm{~cm}$. Noah solves the Richards equation (Richards 1931) to simulate the soil moisture content of each layer through time and allows gravity drainage from the bottom soil layer. The Richards equation is presented here as in Chen et al. (1996):

$$
\frac{\partial \theta}{\partial t}=\frac{\partial}{\partial z}\left[K\left(\frac{\partial \psi}{\partial \theta}\right) \frac{\partial \theta}{\partial z}\right]+\frac{\partial K}{\partial z}+F_{\theta}
$$

where $\theta$ is the volumetric soil moisture (VSM) content $\left(\mathrm{m}^{3} \mathrm{~m}^{-3}\right.$ or $\left.\mathrm{cm}^{3} \mathrm{~cm}^{-3}\right), t$ is time $(\mathrm{s}), z$ is depth $(\mathrm{m})$, and $F_{\theta}\left(\mathrm{cm}^{3} \mathrm{~cm}^{-3} \mathrm{~s}^{-1}\right)$ represents the sum of sources (positive) and sinks (negative): infiltration into and evaporation from the first layer and transpiration from layers that contain roots. The remaining variables $K$ and $\psi$ are the hydraulic conductivity $\left(\mathrm{m} \mathrm{s}^{-1}\right)$ and water tension $\left(\mathrm{m} \mathrm{H}_{2} \mathrm{O}\right)$. Noah uses the Campbell model to define their nonlinear behavior (Campbell 1974):

$$
\begin{aligned}
& \psi=\psi_{\text {sat }}\left(\frac{\theta}{\theta_{\text {sat }}}\right)^{-b} \text { and } \\
& K=K_{\text {sat }}\left(\frac{\theta}{\theta_{\text {sat }}}\right)^{2 b+3} .
\end{aligned}
$$

The four parameters in the above equations are SHPs (Table 1): 1) an empirically determined constant $b$ (unitless), which is related to the pore size distribution; 2) the saturated soil moisture content $\theta_{\text {sat }}\left(\mathrm{cm}^{3} \mathrm{~cm}^{-3}\right)$; 3) the saturated matric potential $\psi_{\text {sat }}\left(\mathrm{m} \mathrm{H}_{2} \mathrm{O}\right)$, which is the water tension at which air enters a saturated volume of soil; and 4) the saturated hydraulic conductivity $K_{\text {sat }}\left(\mathrm{m} \mathrm{s}^{-1}\right)$.

Through Eqs. (1)-(3), SHPs directly affect the flux of water between Noah's soil layers. Each parameter controls one or more aspect of the simulated soil moisture time series. For example, higher $K_{\text {sat }}$ enhances gravitydriven flow, which can result in drier surface soil. Nonlinear interactions between parameters exist, which is one reason why formal calibration schemes may be superior to manual selection of parameter values (Boyle et al. 2000). Prior studies with Noah demonstrate that soil moisture and heat fluxes are sensitive to all four SHPs, whether on their own or through interactions with other parameters (Bastidas et al. 2006; Rosero et al. 2010).

We use hourly NLDAS-2 meteorological forcings (Xia et al. 2012). Default model parameters are either constant or are chosen according to soil texture and vegetation (Table 2). State Soil Geographic (STATSGO)based soil textures and a lookup table from Cosby et al. (1984) provide Noah with its four SHPs at each location (Miller and White 1998; Mitchell et al. 2004). Noah's vegetation parameters are chosen according to the location's University of Maryland $1 \mathrm{~km}$ Land Cover Classification, based on AVHRR data from 1981 to 1994 (Hansen et al. 2000). These consist of rooting depth, minimum and maximum leaf areas, emissivity, albedo, roughness height, and canopy stress parameters. The fractional cover of green vegetation (shdfac) is set to its monthly climatological average from NLDAS Noah forcings between 1979 and 2014.

\section{b. Study sites and soil moisture observations}

Seven sites are used (Table 2): Marena, Oklahoma (Mar); Walnut Gulch, Arizona (WG); Little Washita, Oklahoma (LW); Fort Cobb, Oklahoma (FC); Little River, Georgia (LR); St. Josephs, Indiana (SJ); and Reynolds Creek, Idaho (RC). At each site, surface soil moisture data are available from 1) a network of in situ probes operated by the U.S. Department of Agriculture Agricultural Research Service (USDA-ARS) and 2) the ESA's SMOS satellite mission (Kerr et al. 2010a). Soil moisture is reported as VSM $\left(\mathrm{cm}^{3} \mathrm{~cm}^{-3}\right)$, representing the ratio between volume of water and total soil volume.

A primary goal of these in situ networks is calibration and validation of satellite products. Each has a distributed network of Stevens Water Hydra Probes placed at $5 \mathrm{~cm}$ depth and an upscaling function that qualifies it for use at the 36-km scale (Colliander et al. 2015). The networks" "basin" average is thus representative of a passive microwave satellite footprint (Jackson et al. 2010). Supporting studies have determined most of the networks (WG, LW, LR, and RC) represent soil moisture with high accuracy $\left(\sim 0.01 \mathrm{~cm}^{3} \mathrm{~cm}^{-3}\right)$ from 0 to $5 \mathrm{~cm}$ (Jackson et al. 2012; Cosh et al. 2006, 2008; Bosch et al. 2006). FC has been shown to perform well in a multiyear 


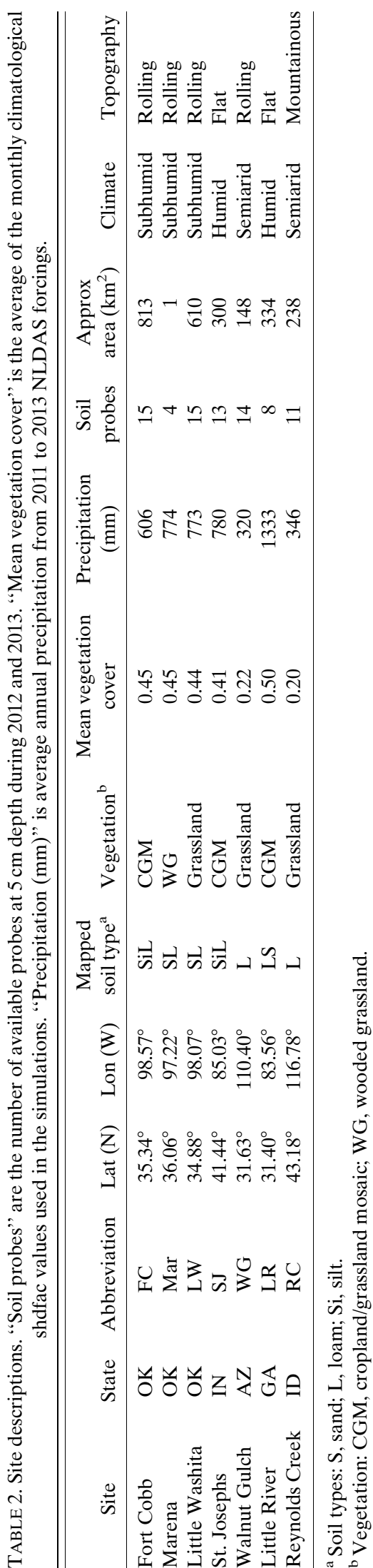

stability study, though it has not been explicitly validated (Cosh et al. 2014). SJ is still under development, but its design and instrumentation are similar to the other sites.

Each sites' $5-\mathrm{cm}$ in situ averages are used for SHP calibration. When available, we also use probes from lower in the soil column to evaluate performance of the calibrated models. Five of the seven sites have deeper probes. We assign these to represent the second model layer $(10-40 \mathrm{~cm})$ as follows: when two probes fall within the second model layer, they are averaged. When only one exists, it represents the entire layer. For both soil layers, multiple probe locations contribute to the network's average. Observations are recorded hourly, but for direct comparison with SMOS observations, only 0600 LT (local time) observations are used each day. Hereafter, in situ VSM refers to the daily, networkaveraged soil moisture.

SMOS uses a passive, synthetic aperture, L-band radiometer to retrieve soil moisture every $\sim 3$ days with spatial resolution of $\sim 1200 \mathrm{~km}^{2}$ (Jackson et al. 2012). The radiometer measures microwave brightness temperature, which is then converted into a soil moisture value according to the relationship outlined by Jackson and Schmugge (1989) and detailed in Kerr et al. (2010b). Vegetation affects the retrievals, but corrections for vegetation are possible when vegetation water content is less than $5 \mathrm{~kg} \mathrm{~m}^{-2}$ (Kerr et al. 2010a). SMOS has a sunsynchronous orbit, which passes over the equator at approximately 0600 (ascending) and 1800 LT (descending). The SMOS algorithm's underlying equations are based on an assumption of uniform soil moisture and soil/vegetation temperature over the sensing depth. The ground surface is closest to meeting this assumption when it has had maximal time to equilibrate from the previous day's fluxes (Jackson et al. 2012; Jackson 1980). We therefore use the ascending (0600 LT) level 3 soil moisture data, which are provided by the Centre Aval de Traitement des Données SMOS.

\section{c. Calibration strategy and experiments}

The general format for model calibration to a single observational time series has been detailed in Vrugt et al. (2008). We calibrate the four SHPs in Table 1. Posterior distributions have limited sensitivity to prior distributions (Harrison et al. 2012), so for simplicity, priors are taken to be uniform between two bounds. We use similar parameter ranges to those used by Harrison et al. (2012), except that the ranges of $\psi_{\text {sat }}$ and $K_{\text {sat }}$ priors are narrowed to avoid unrealistic second-layer soil moisture contents observed in some preliminary experiments. The range of parameter values in the calibration scheme is purposefully larger than the range of 
mean values used in default Noah simulations (Table 1). This allows for increased parameter diversity and potential advantages to calibrated values.

We calibrate SHPs by minimizing the differences between surface soil moisture observations and simulations. We quantify their differences with an objective function (OF), which we choose to be the RMSD:

$$
\mathrm{RMSD}=\sqrt{\frac{\sum\left(\mathrm{VSM}_{\mathrm{sim}}-\mathrm{VSM}_{\mathrm{obs}}\right)^{2}}{n},}
$$

where sim and obs indicate the simulated and observed VSM, respectively, and $n$ is the number of days that both are available. RMSD is used in many hydrologic calibration studies (Burke et al. 1997; Gupta et al. 1998; Santanello et al. 2007; Peters-Lidard et al. 2008; Gutmann and Small 2010; Harrison et al. 2012) and is a convenient way to measure dispersion of the model residual around zero (Gupta et al. 1998). As in Albergel et al. (2012), we use the terminology RMS difference, instead of RMS error, because observations do not represent true soil moisture.

We use the Differential Evolution Adaptive Metropolis (DREAM) algorithm to search the parameter space using 50000-100000 model simulations (Vrugt et al. 2008, 2009). Each simulation is 2 years long: a calibration year (2012) following a 1-yr spinup (2011). The spinup is sufficiently long for Noah SHP calibration purposes (Gutmann and Small 2010). The exact number of simulations depends on the $\hat{R}$ statistic of Gelman and Rubin (1992), indicating convergence to a stationary posterior distribution. We ensure at least 2500 additional model simulations after convergence to characterize the posterior distributions of the parameters in each experiment. Simulations from converged parameter sets are run for an additional year (2013) for validation against in situ soil moisture.

The DREAM algorithm's lineage includes the University of Arizona Shuffled Complex Evolution (SCEUA) and Shuffled Complex Evolution Metropolis (SCEM-UA) parameter estimation algorithms (Duan et al. 1992; Vrugt et al. 2003). It is distinct in its ability to provide posterior parameter distributions, which we use to quantify uncertainty in our analyses.

At each study site, both in situ and remotely sensed surface soil moisture observations are available. With these two sources, we produce three calibration experiments:

1) In situ: Minimize the OF between simulated and in situ surface soil moisture. The calibration and validation observations are from the same soil probes. This experiment therefore provides an upper limit to model performance at each site in the validation period.
2) SMOS: Minimize the OF between simulated and remotely sensed soil moisture from the SMOS pixel centered on each field site.

3) SMOS $_{\text {adj }}$ : Minimize the OF between simulated soil moisture and a bias-free SMOS product. The SMOS soil moisture time series has been adjusted through a translation of the observations so that the mean of the 2012 SMOS and in situ observations are equal. Bias removal is completed on a site-by-site basis. In the rare cases when a shifted moisture value would drop below zero, it is limited to zero. This experiment shows the potential of a bias-free SMOS time series in our calibration framework.

Experiments produce posterior distributions for each parameter. The single best parameter set is the one whose simulation produces the maximum a posteriori probability (MAP; in this case, lowest RMSD) in the calibration period. The associated model run is referred to as the calibrated simulation.

\section{d. Texture-based simulations}

A site's soil texture designation (and thus SHPs) may differ between global maps, local maps, and site observations (Guillod et al. 2013; Xia et al. 2015). We therefore carry out simulations using all 12 possible texture designations at each site. These parameter sets and their resulting simulations are hereafter called "texture based." They allow us to illustrate the range of states and fluxes that are possible for a given location using the current parameterization strategy. At each site, we highlight two of these texture-based simulations: 1) the default texture, which is used by NLDAS simulations, and 2) the best texture, which minimizes the RMSD between simulated and in situ surface VSM in the calibration period.

The best texture simulation allows the calibration results to be compared with those of an improved texture. We acknowledge that the best texture cannot be determined in this fashion at sites that do not have soil moisture instrumentation.

\section{e. Assessment of model calibrations}

We use the following:

1) RMSD between simulated and in situ VSM. While the in situ soil moisture is not without its own measurement and averaging errors, it is our only proxy for the true surface soil moisture.

2) The arithmetic mean of VSM time series. This metric provides insight into how minimizing RMSD affects moisture biases.

3) RMSD between simulated and in situ VSM anomalies [unbiased RMSD (ubRMSD)]. UbRMSD provides a 
measure of how well each simulation captures soil moisture dynamics. We calculate ubRMSD both for the validation year as a whole (year-long ubRMSD) and on a moving 90-day window throughout the validation period (windowed ubRMSD). The latter method identifies the time periods when calibration yields the greatest improvements.

\section{f. Study limitations and sources of error}

\section{1) RePresentativenESS AND ACCURACY OF DATA PRODUCTS}

Soil moisture variability increases with scale, so representative basinwide in situ values require many observations (Famiglietti et al. 2008). The monitoring sites used in this study are the best available, but they cannot be perfect. Moreover, results from Mar must be considered differently. The probe type and installation depth match the other sites, but Mar only includes four sensors distributed across a $1 \mathrm{~km}^{2}$ area. We include this location to identify what useful information (if any) can be gleaned from a site whose representative area is intermediate between a remotely sensed pixel and a single probe.

The SMOS mission's target accuracy of $0.04 \mathrm{~cm}^{3} \mathrm{~cm}^{-3}$ RMSD is not met at all sites. In 2010, at WG, LW, LR, and RC, RMSD values were $0.038,0.042,0.051$, and $0.039 \mathrm{~cm}^{3} \mathrm{~cm}^{-3}$, respectively, and biases were $0.003,0.002$, 0.026 , and $-0.023 \mathrm{~cm}^{3} \mathrm{~cm}^{-3}$, respectively (Jackson et al. 2012). Elsewhere in North America, SMOS biases of up to $-0.12 \mathrm{~cm}^{3} \mathrm{~cm}^{-3}$ have been documented (Albergel et al. 2012; Collow et al. 2012; Al Bitar et al. 2012).

In situ, remotely sensed, and modeled depths are not identical. The $5-\mathrm{cm}$ in situ probes measure over a depth of approximately $3-7 \mathrm{~cm}$. This is similar to the first model layer, $0-10 \mathrm{~cm}$. The correspondence between remotely sensed and modeled VSM is not as exact. SMOS retrieval depth is approximately $5 \mathrm{~cm}$. However, the sensing depth decreases after rainfall when the surface layer is nearly saturated and increases to more than $5 \mathrm{~cm}$ when the soil is dry (Jackson et al. 2012). To assess the significance of this difference, we have completed our parameter estimation analysis with the Noah first layer thickness set to $0-5 \mathrm{~cm}$ instead of $0-10 \mathrm{~cm}$. We find that this change leads to trivial differences in both simulated soil moisture time series and parameter distributions. We continue with $0-10 \mathrm{~cm}$ thickness to avoid modifying the standard model setup and to make our findings directly applicable to NLDAS Noah simulations.

Finally, we note that the spatial resolution of NLDAS-2 is finer than that of SMOS. Figure S1 in the supplemental material shows the different spatial coverages of in situ, SMOS, and NLDAS data for all sites except Mar, which, as mentioned above, is of a different spatial scale.

\section{2) Calibration scheme}

Adjusting specific parameters can compensate for errors in other parameters, model structure, or input data (Doherty and Welter 2010). The DREAM algorithm limits the user to one OF, which has additional weaknesses compared to multiobjective schemes: calibration can lead to compensating biases in other aspects of the system, such as LHF and runoff (Wöhling et al. 2013; Gupta et al. 1999; Salvucci and Entekhabi 2011). In turn, changes to LHF of $15-20 \mathrm{~W} \mathrm{~m}^{-2}$ can have a significant impact on atmospheric processes (Schär et al. 1999). Despite these disadvantages, we wish to study the potential of SMOS soil moisture in a single-objective scheme before combining it with other constraining states or fluxes. We lack observations of surface runoff, base flow, and LHF, so a comprehensive evaluation of all model fluxes is admittedly not possible. However, these are high-quality soil moisture networks, and they thus provide unique and powerful constraints on SHPs. We supplement the validation by qualitatively assessing the effects that calibrated parameter sets have on discharge and LHF.

Even a model with ideal parameters may have structural inadequacies and meteorological forcing errors. The latter has been shown to account for $20 \%-60 \%$ of soil moisture prediction uncertainty (Hossain and Anagnostou 2005). Finally, parameters selected through calibration are not easily transferable to other scales or ungauged locations (Liang et al. 2004; Troy et al. 2008). To mitigate these problems, we have included a variety of locations in this study, and in situ scales are roughly commensurate with forcing data.

\section{Results}

\section{a. Improvement of surface soil moisture}

Surface VSM results are exclusively from the validation period and compare simulations with in situ observations.

\section{1) RMSD}

Figure 1 shows an example of the calibration results at SJ. We include soil moisture time series from the three calibrations as well as the 12 texture-based simulations. The site's default soil texture, silty loam, is far from the best: RMSD is $0.059 \mathrm{~cm}^{3} \mathrm{~cm}^{-3}$. Five other textures yield better soil moisture simulations. The best texture is sandy loam, with an RMSD of $0.048 \mathrm{~cm}^{3} \mathrm{~cm}^{-3}$. Thus, by changing the soil texture designation, we can reduce 


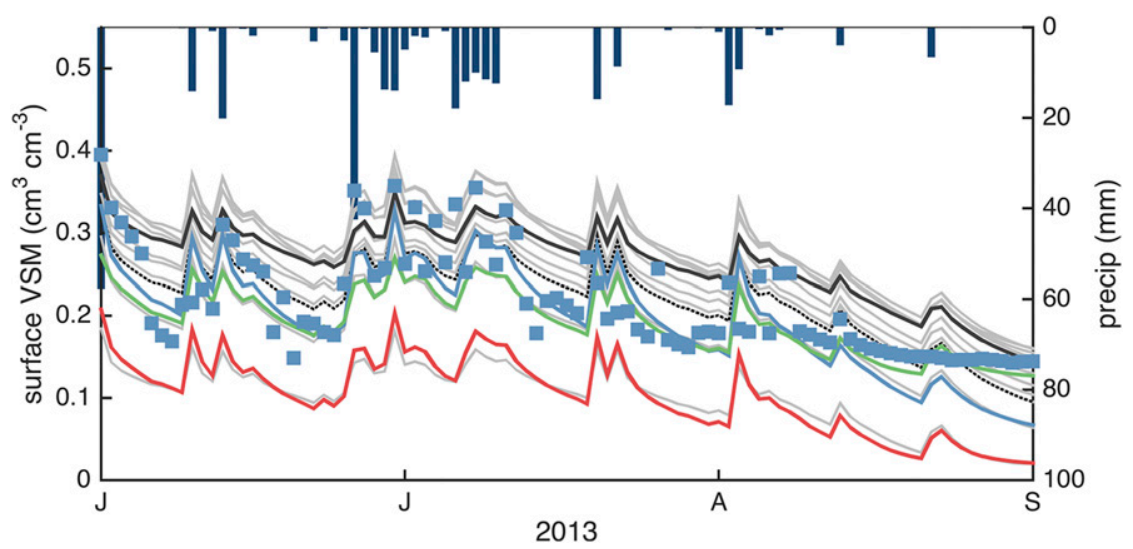

FIG. 1. An example time series at SJ. Shown are the basin-averaged in situ surface soil moisture measurements (blue squares), the texture-based simulations (gray lines), the default simulation (silty loam; black solid line), the best texture simulation (sandy loam; black dotted line), and the three calibrated time series (blue indicates in situ, red indicates SMOS, and green indicates $\mathrm{SMOS}_{\mathrm{adj}}$ ). Precipitation is shown by dark blue bars.

model error by nearly $20 \%$. Similar results are found at all seven sites (Fig. 2, Table 3). At no site is the default texture the same as the best texture. RMSDs for the default simulations range from 0.03 to $0.11 \mathrm{~cm}^{3} \mathrm{~cm}^{-3}$ (mean $0.07 \mathrm{~cm}^{3} \mathrm{~cm}^{-3}$ ). If the best texture were used at each site, error would decrease by an average of $0.03 \mathrm{~cm}^{3} \mathrm{~cm}^{-3}$, bringing all but the RC simulation below $0.05 \mathrm{~cm}^{3} \mathrm{~cm}^{-3}$, the low end of the RMSD range found in default simulations by Xia et al. (2015). Such improvement from switching soil type reflects a general failure of using mapped soil texture to select SHPs but not necessarily a problem with the 12 texture-based parameter sets themselves.

As expected, calibration to in situ observations improves simulated soil moisture. For example, the best in situ calibrated soil moisture time series at SJ (blue line, Fig. 1) more closely follows the in situ observations than the default simulation does. Across all sites, RMSD improves by an average of $0.03 \mathrm{~cm}^{3} \mathrm{~cm}^{-3}$. All but $\mathrm{RC}$ are brought below $0.05 \mathrm{~cm}^{3} \mathrm{~cm}^{-3}$. The improvements from in situ calibration at each site are only slightly better than the improvements made by replacing the default soil texture with the best texture. At sites where the default simulation performs well (Mar and LW), calibration changes the RMSD very little. Equally important, these best sites are not made worse through calibration. Sites with poor default simulations benefit the most from calibration (WG, LR, and RC).

Calibration to SMOS observations does not consistently improve RMSD. At SJ, the SMOS-calibrated soil moisture is far below the in situ observations (red line, Fig. 1). FC, WG, and RC are improved through SMOS calibration (Fig. 2, Table 3), but an equal number are made worse (Mar, SJ, and LR). The average change to RMSD is close to zero.
At all seven sites, calibration to $\mathrm{SMOS}_{\text {adj }}$ observations results in a lower RMSD than the default simulations (Fig. 2, Table 3). The average improvement is $0.03 \mathrm{~cm}^{3} \mathrm{~cm}^{-3}$.

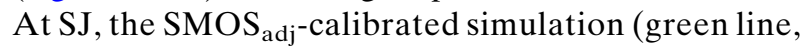
Fig. 1) is better than the default and SMOS-calibrated simulations. Like simulations calibrated to in situ, the sites already performing well (Mar and LW) maintain their good performance when calibrated to SMOS $_{\text {adj. }}$.

While RMSD establishes model error, it does not explicitly address how well model variability matches observations. To this end, we have calculated coefficient

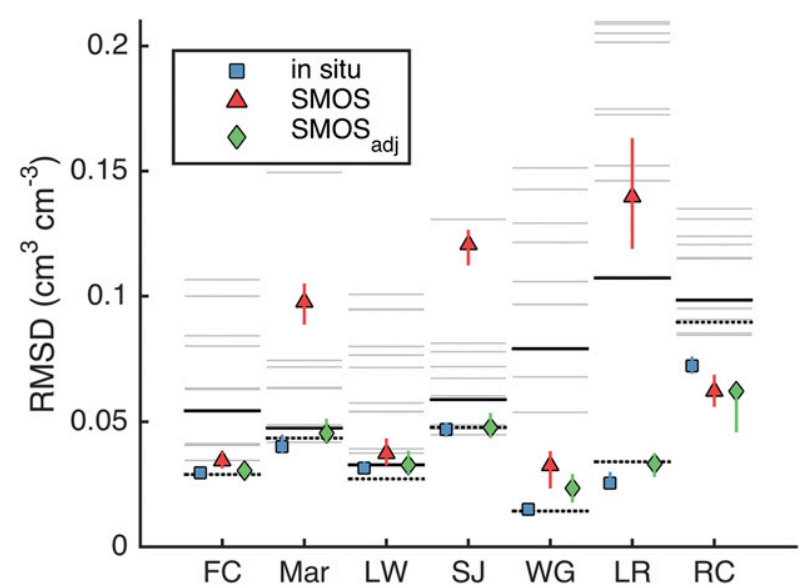

FIG. 2. RMSD between simulations and in situ soil moisture at each site in the validation period. Simulations include texture based (gray lines), default (black solid lines), best texture (black dotted lines), in situ calibrated (blue squares), SMOS calibrated (red triangles), and SMOS $_{\text {adj }}$ calibrated (green diamonds). Error bars show the range of performances from each calibration's stable posterior parameter distribution. 
TABLE 3. RMSD between simulations and observed in situ soil moisture during the validation period. For readability, all values are expressed as hundredths of $\mathrm{cm}^{3} \mathrm{~cm}^{-3}$ (divide by 100 for actual values). Change $\Delta$ is with respect to the default simulation. Boldface indicates improvement of at least $0.005 \mathrm{~cm}^{3} \mathrm{~cm}^{-3}$ (or 0.5 in the table); italics indicate degradation of at least $0.005 \mathrm{~cm}^{3} \mathrm{~cm}^{-3}$.

\begin{tabular}{|c|c|c|c|c|c|c|c|c|c|c|c|}
\hline \multirow[b]{2}{*}{ Site } & \multicolumn{2}{|c|}{ Default texture } & \multicolumn{3}{|c|}{ Best texture } & \multicolumn{2}{|c|}{ In situ } & \multicolumn{2}{|c|}{ SMOS } & \multicolumn{2}{|c|}{ SMOS $_{\text {adj }}$} \\
\hline & Class $^{\mathrm{a}}$ & RMSD & Class $^{\mathrm{a}}$ & RMSD & $\Delta$ & RMSD & $\Delta$ & RMSD & $\Delta$ & RMSD & $\Delta$ \\
\hline $\mathrm{FC}$ & $\mathrm{SiL}$ & 5.4 & LS & 2.9 & -2.5 & 3.0 & -2.5 & 3.4 & -2.0 & 3.0 & -2.4 \\
\hline Mar & SL & 4.8 & SCL & 4.4 & -0.4 & 4.0 & -0.7 & 9.8 & 5.0 & 4.6 & -0.2 \\
\hline LW & SL & 3.3 & LS & 2.7 & -0.6 & 3.2 & -0.1 & 3.7 & 0.5 & 3.3 & 0.0 \\
\hline SJ & $\mathrm{SiL}$ & 5.9 & SL & 4.8 & -1.1 & 4.7 & -1.2 & 12.1 & 6.2 & 4.8 & -1.1 \\
\hline WG & $\mathrm{L}$ & 7.9 & $\mathrm{~S}$ & 1.4 & -6.5 & 1.5 & -6.4 & 3.3 & -4.7 & 2.3 & -5.6 \\
\hline LR & LS & 10.7 & $\mathrm{~S}$ & 3.4 & -7.3 & 2.6 & -8.2 & 14.0 & 3.3 & 3.3 & -7.4 \\
\hline $\mathrm{RC}$ & $\mathrm{L}$ & 9.8 & LS & 9.0 & -0.0 & 7.2 & -2.6 & 6.2 & -3.6 & 6.2 & -3.6 \\
\hline Mean & & 6.8 & & 3.9 & -2.8 & 3.7 & -3.1 & 7.5 & 0.7 & 3.9 & -2.9 \\
\hline
\end{tabular}

a Soil types: S, sand; L, loam; Si, silt; C, clay.

of determination $R^{2}$ values for all simulations shown in Fig. 2, and the results are effectively the same (Fig. S2).

\section{2) MEAN VSM}

Figure 3a shows how the mean VSM of each simulation compares with the mean of the in situ observations. For all texture-based and calibrated simulations except RC, the closer the match between simulated and observed mean VSM, the lower the RMSD is. In this light, it is not surprising that the SMOS retrievals cannot be used to successfully select SHPs, since the SMOS retrievals often have biases with respect to the in situ observations. Sites whose SMOS-calibrated simulations have a greater RMSD than default simulations are Mar, SJ, and LR. They also have the worst SMOS biases: $-0.064,-0.101$, and $0.136 \mathrm{~cm}^{3} \mathrm{~cm}^{-3}$, respectively. SMOS biases at FC, LW, WG, and RC are smaller: $-0.008,-0.008,0.013$, and $-0.049 \mathrm{~cm}^{3} \mathrm{~cm}^{-3}$.
At these sites, the SMOS and SMOS $_{\text {adj }}$ calibrations are similarly successful at reducing or not changing RMSD.

These results qualify the utility of SMOS data. The success of the SMOS ${ }_{\text {adj }}$ calibrations is in large part due to their unbiased nature, a characteristic imposed on the calibration data by design prior to the experiment.

\section{3) UBRMSD}

We must determine the value of SMOS observations independent of their biases. Figure 4 shows VSM anomalies. The model does not capture the wetting events near the end of June nor the drying period at the end of August, no matter what parameter set is used. We quantify such temporal dynamics in each simulated VSM time series using year-long and windowed ubRMSD.

We first summarize the year-long ubRMSD results (Fig. 3b, Table 4). The best texture simulations do not minimize year-long ubRMSD at all sites. At Mar, SJ, and $\mathrm{RC}$, a number of textures would have produced
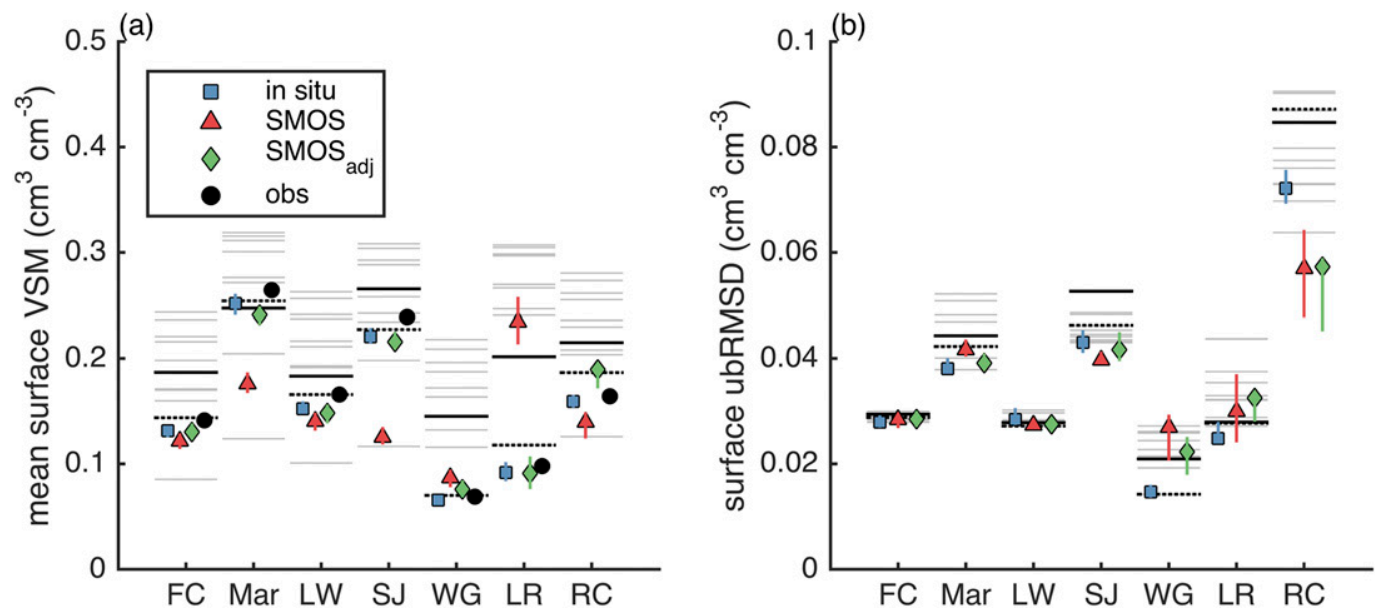

FIG. 3. (a) Mean VSM and (b) year-long ubRMSD in the surface layer. Symbols and lines are as in Fig. 2, with in situ observations also included as black circles. 


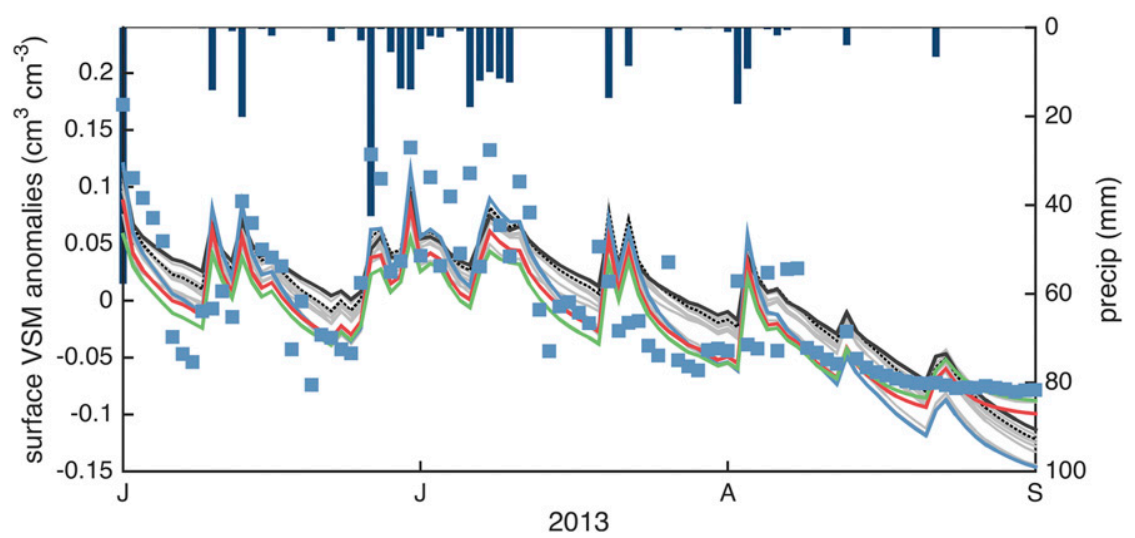

FIG. 4. As in Fig. 1, but with the mean of each time series removed.

lower ubRMSDs than the best texture did. This failure indicates that minimization of RMSD does not require minimization of ubRMSD. It only requires a good match between mean values of the time series.

Calibrated soil moisture curves at most sites either do not change or improve the year-long ubRMSD over the default simulation. In five experiments, calibrated simulations improve year-long ubRMSD more than any texture-based simulation can: SJ calibrated to in situ and

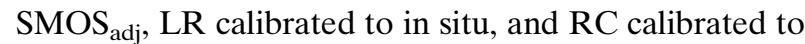

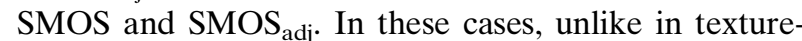
based simulations, minimization of RMSD does not merely match simulated and observed mean VSM. It has the additional effect of improving soil moisture dynamics.

At the other extreme are FC and LW, whose calibrated and texture-based simulations all have the same year-long ubRMSD. Despite a wide range of RMSDs, all simulations have identical abilities to capture soil moisture dynamics. RMSD and the calibration process at these sites therefore depend entirely on the match with in situ mean VSM.

Changes to year-long ubRMSD are not large. The windowed ubRMSD, however, exposes notable improvements to calibrated simulations' soil moisture dynamics. We see the largest improvements occurring at sites and times of year when the default simulation is worst. Figure 5 compares the default simulation's windowed ubRMSD to that of the three calibrated and best texture simulations at SJ. The default simulation has the highest ubRMSD around March and April, which are times of year when all three calibrated simulations show the largest improvements to windowed ubRMSD. The best texture simulation, on the other hand, has mixed, small effects on ubRMSD throughout the year, regardless of the default simulation's performance.

Beyond SJ, improvements to ubRMSD are made at all sites and time periods when the default windowed ubRMSD is poor. In addition, ubRMSD is not made worse when the default simulation is good. In Fig. 6, the $x$ axis shows the windowed ubRMSD of the default simulation for all validation days. The $y$ axis shows the changes that each calibration or best texture would make on each day (negative numbers indicate improvement). We use a black dotted line to define a threshold default ubRMSD at $0.04 \mathrm{~cm}^{3} \mathrm{~cm}^{-3}$. We average the windowed ubRMSD both below and above this threshold, shown with the solid colored lines. Below the threshold, where the default simulations are good, all calibrations have a mixed, small effect on ubRMSD. There are no increases greater than $0.005 \mathrm{~cm}^{3} \mathrm{~cm}^{-3}$ at

TABLE 4. As in Table 3, but for ubRMSD and without soil class.

\begin{tabular}{|c|c|c|c|c|c|c|c|c|c|}
\hline \multirow[b]{2}{*}{ Site } & \multirow{2}{*}{$\frac{\text { Default texture }}{\text { ubRMSD }}$} & \multicolumn{2}{|c|}{ Best texture } & \multicolumn{2}{|c|}{ In situ } & \multicolumn{2}{|c|}{ SMOS } & \multicolumn{2}{|c|}{ SMOS $_{\text {adj }}$} \\
\hline & & ubRMSD & $\Delta$ & ubRMSD & $\Delta$ & ubRMSD & $\Delta$ & ubRMSD & $\Delta$ \\
\hline $\mathrm{FC}$ & 2.9 & 2.9 & -0.06 & 2.8 & -0.15 & 2.8 & -0.10 & 2.9 & -0.09 \\
\hline Mar & 4.4 & 4.2 & -0.20 & 3.8 & -0.63 & 4.2 & -0.26 & 3.9 & -0.51 \\
\hline LW & 2.8 & 2.7 & -0.06 & 2.8 & 0.06 & 2.7 & -0.04 & 2.8 & -0.03 \\
\hline SJ & 5.3 & 4.6 & -0.63 & 4.3 & -0.96 & 4.0 & -1.29 & 4.2 & -1.10 \\
\hline WG & 2.1 & 1.4 & -0.67 & 1.5 & -0.62 & 2.7 & 0.60 & 2.2 & 0.14 \\
\hline LR & 2.8 & 2.8 & -0.02 & 2.5 & -0.31 & 3.0 & 0.20 & 3.3 & 0.46 \\
\hline $\mathrm{RC}$ & 8.5 & 8.7 & 0.25 & 7.2 & -1.25 & 5.7 & -2.78 & 5.7 & -2.75 \\
\hline Mean & 4.1 & 3.9 & -0.2 & 3.6 & -0.55 & 3.6 & -0.52 & 3.6 & -0.55 \\
\hline
\end{tabular}



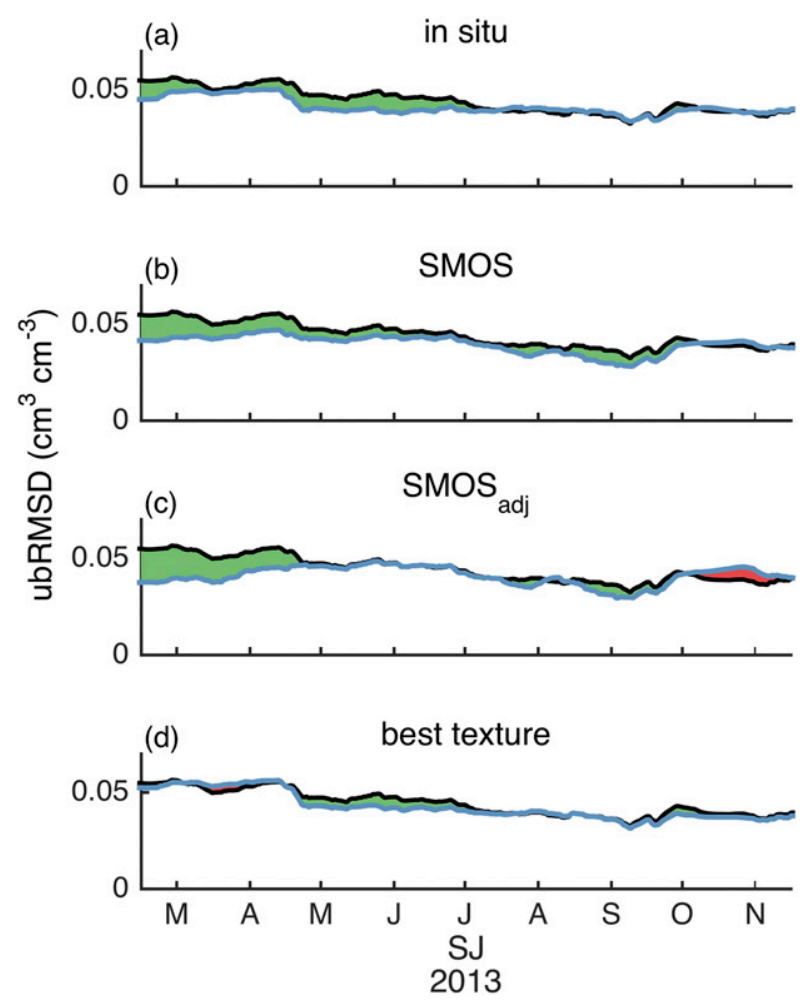

FIG. 5. Windowed ubRMSD at SJ, from the (a) in situ,

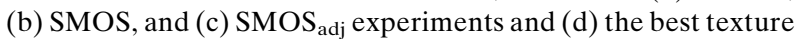
simulation. Default simulation is shown in black. Calibrated and best texture simulations are shown in blue. Green shading highlights periods when the calibrated or best texture simulation is better than the default simulation. Red shading shows the reverse.

any site. Above the threshold, which is crossed at Mar, SJ, and RC, calibrated simulations have a lower ubRMSD than default simulations do, by as much as $0.026 \mathrm{~cm}^{3} \mathrm{~cm}^{-3}$. We highlight this region of the plot by shading it yellow. In contrast, the best texture simulations do not improve ubRMSD at times when the default simulation is above the threshold. Improvement at Mar and SJ are present but small. At RC, the best texture is worse even than the default simulation.

\section{b. Changes to other model states and fluxes}

In this section, we describe the effects of calibration on deeper soil moisture, runoff, and LHF. Because none of these three variables were involved in calibration, the following results utilize modeled data from both the calibration and validation periods.

\section{1) DeEPer SOIL MOISTURE}

The $10-40 \mathrm{~cm}$ in situ data have not been verified as an accurate measurement of the second model layer's VSM. We therefore assess performance with ubRMSD
(Fig. 7a), which depends only on changes to soil moisture, not absolute VSM values. The best texture simulations have no consistent effect on second-layer dynamics. FC, Mar, and LW stay the same; SJ is made worse; and LR is improved. Calibrated simulations do not harm the model's second-layer dynamics and often slightly improve them. Only the in situ calibration at SJ is made worse.

Figure $7 \mathrm{~b}$ shows the mean second-layer VSM for all simulations. The calibrated simulations produce drier second-layer VSM than the default in all cases except the in situ and SMOS $_{\text {adj }}$ calibrations at Mar and the SMOS calibration at LR. The best texture simulations also decrease mean second-layer moisture at all sites except Mar. The deeper (third and fourth) soil layers are similarly affected (not shown). For reference, we also show the mean in situ soil moisture, which can be either drier or wetter than the default simulation, although these in situ observations cannot be considered as truth.

\section{2) RUNOFF AND LHF}

Conservation of mass requires that changes to soil moisture magnitudes and dynamics be associated with changes in runoff and LHF. We look first at each site's surface runoff, subsurface runoff, and total runoff ratio (Fig. 8). With only two exceptions (in situ at WG and SMOS $_{\text {adj }}$ at LR), calibrated simulations have more surface runoff than default simulations do. This change corresponds to an increase in the runoff ratio (total runoff/total precipitation) for all experiments except in situ and SMOS ${ }_{\text {adj }}$ at Mar, and SMOS at LR, which have counteracting decreases in subsurface runoff. We include runoff ratios from all 12 texture-based simulations at each site to illustrate the range of values possible without calibration. The calibrated simulations are mostly at the high end of this range. In contrast, the best textures produce simulations whose runoff ratios are more often at the low end or in the middle of this range.

Figure 9 shows the differences in each simulation's mean daily summertime LHF. We focus on summer because that is the season in which LHF is greatest. The range of LHF produced by the 12 texture-based parameters is generally less than $15-20 \mathrm{~W} \mathrm{~m}^{-2}$, and the best texture is at most only $8.3 \mathrm{~W} \mathrm{~m}^{-2}$ different from the default simulation. On the other hand, three of the seven sites have significantly lower $\left(>20 \mathrm{~W} \mathrm{~m}^{-2}\right)$ LHF values after calibration: FC, SJ, and LR. The remaining four sites have changes to LHF that are relatively small (less than $10 \mathrm{~W} \mathrm{~m}^{-2}$ ). We do not have flux tower data at all sites to determine whether LHF should be much different from that of the default simulation, but together the increased surface runoff and decreased LHF data 

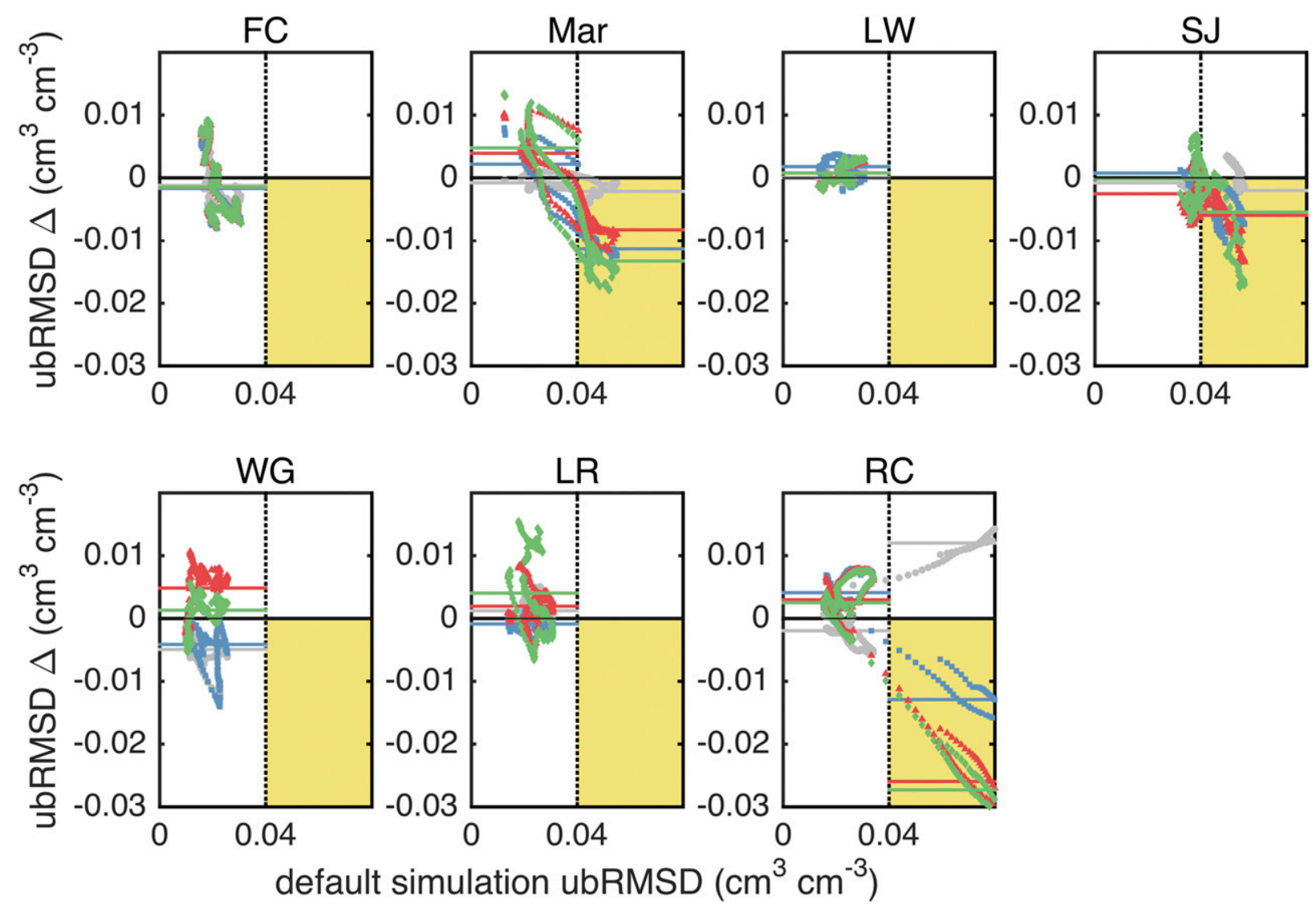

FIG. 6. The default simulation's windowed ubRMSD and the change $\Delta$ that four alternative simulations can make: in situ calibrated (blue squares), SMOS calibrated (red triangles), SMOS $_{\text {adj }}$ calibrated (green diamonds), and best texture (gray circles). Dotted line shows $0.04 \mathrm{~cm}^{3} \mathrm{~cm}^{-3}$ threshold. Colored horizontal lines show mean values on each side of the threshold. Yellow shading shows where the default is worst and can be improved.

indicate that calibrated parameters allow less water to pass through the soil column during rainfall events.

\section{c. Parameter values and trends}

The DREAM algorithm, in addition to identifying a MAP value, produces a posterior probability distribution for each experiment. Similarly, Cosby et al. (1984) provide not only the mean of each texture class but also standard deviations. We illustrate the differences between each distribution using $\theta_{\text {sat }}$ as an example, which contains some commonalities that hold true for all four SHPs (Fig. 10). The supplemental material contains all default and calibrated parameter values in Table S1. It also includes Figs. S3-S5, which show the posterior distributions of the other three parameters. At most sites, the calibrated parameters occupy a narrower range than they do in the laboratory measurements of Cosby et al. (1984). Moreover, most MAP parameter values fall within the Gaussian distribution of the prescribed texture class, evidence that the calibrated parameter values are reasonable estimates. The remainder of this section focuses on summarizing the differences between MAP values and texture class mean values.

Except for SMOS ${ }_{\mathrm{adj}}$ at LR, all experiments and all best textures result in $\theta_{\text {sat }}$ being lower than its default assignment. We show in Fig. 11 that this parameter correlates well with the mean VSM of its calibration time series, which is lower than that of the default simulation in almost all cases (Fig. 3a). We include a line connecting the in situ and SMOS data at each site to show that this relationship is always positive within a location. The $\operatorname{SMOS}_{\text {adj }} \theta_{\text {sat }}$ values fall between those of the in situ and SMOS calibrations; SMOS $_{\text {adj }}$ is a hybrid of the two observational time series. The $\mathrm{SMOS}_{\mathrm{adj}}$ calibration at LR is clearly visible here as an outlier.

All calibrated $K_{\text {sat }}$ parameters are lower than the default values with only two exceptions: SMOS $_{\text {adj }}$ calibration at LR and in situ at WG. In contrast, the best texture values are all higher than the default values, except at Mar. This division is the most distinct of the four parameters, and we address its implications in the discussion. 

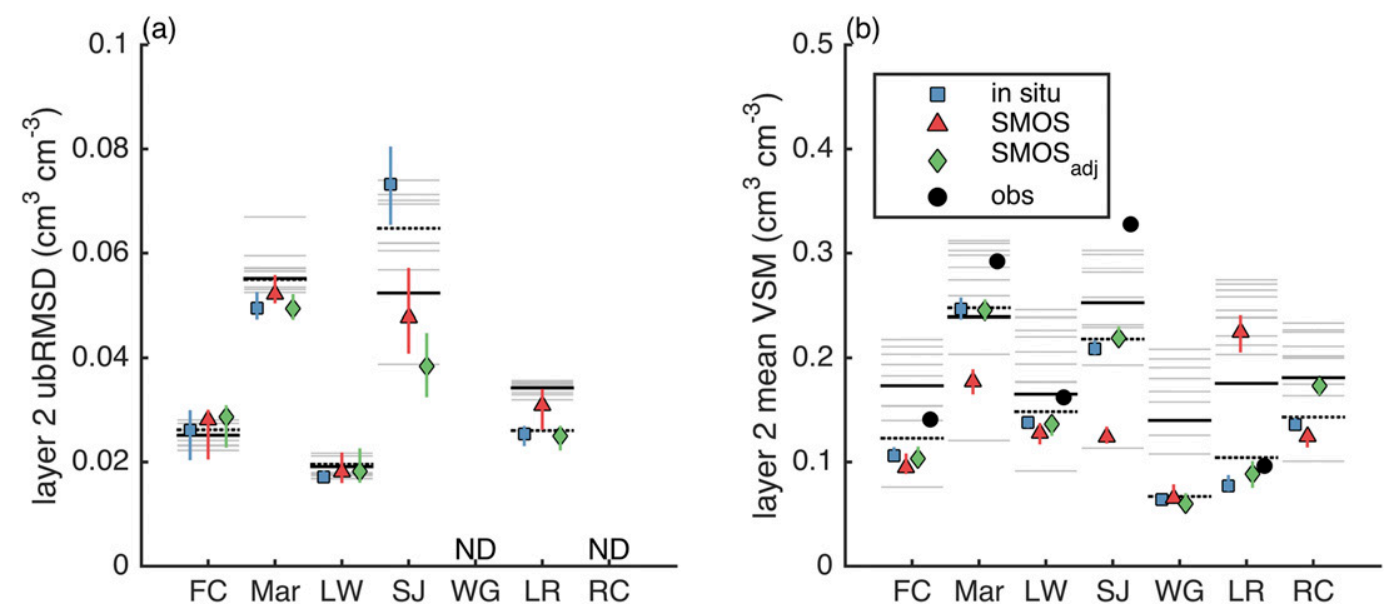

FIG. 7. (a) UbRMSD and (b) mean VSM in second model layer. ND indicates no data are available below $10 \mathrm{~cm}$. Symbols and lines are as in Fig. 2, with in situ observations also included as black circles.

Neither $b$ nor $\psi_{\text {sat }}$ change much with calibration. The value of $b$ remains similar to the default value, and $\psi_{\text {sat }}$ values are similar or slightly lower. For both, however, the best texture values are consistently lower than the default. The only exception for $b$ is Mar, where it is slightly higher, and for $\psi_{\text {sat }}$ is LR, where it already had the lowest possible value.

\section{d. Nonbehavioral simulations at LR}

LR has a number of problems with its calibrated simulations and parameters. Figure 12 shows the observational time series, default simulation, and rainfall at LR. The rainfall and vegetative cover are higher than at any other site (Table 1). The in situ observations are lower than all but the arid WG site. The default simulation, likely because of this inconsistency, is poor, having a higher RMSD than any other location (Fig. 2).

In all three LR calibration experiments, parameter values move away from the default, and simulations are nonbehavioral. When LR is calibrated to in situ, there is more than twice as much surface runoff as in any other simulation, and summer LHF decreases by $20 \mathrm{~W} \mathrm{~m}^{-2}$. When LR is calibrated to SMOS, the simulation's surface soil moisture RMSD becomes higher than that of any other. Also, the value of the $b$ parameter reaches its upper limit, which may not be physically realistic. Finally, when LR is calibrated to SMOS $_{\mathrm{adj}}$, the resulting simulation has 1.5 times the subsurface runoff than the next highest simulation, and summer LHF decreases by more than $20 \mathrm{Wm}^{-2}$. In
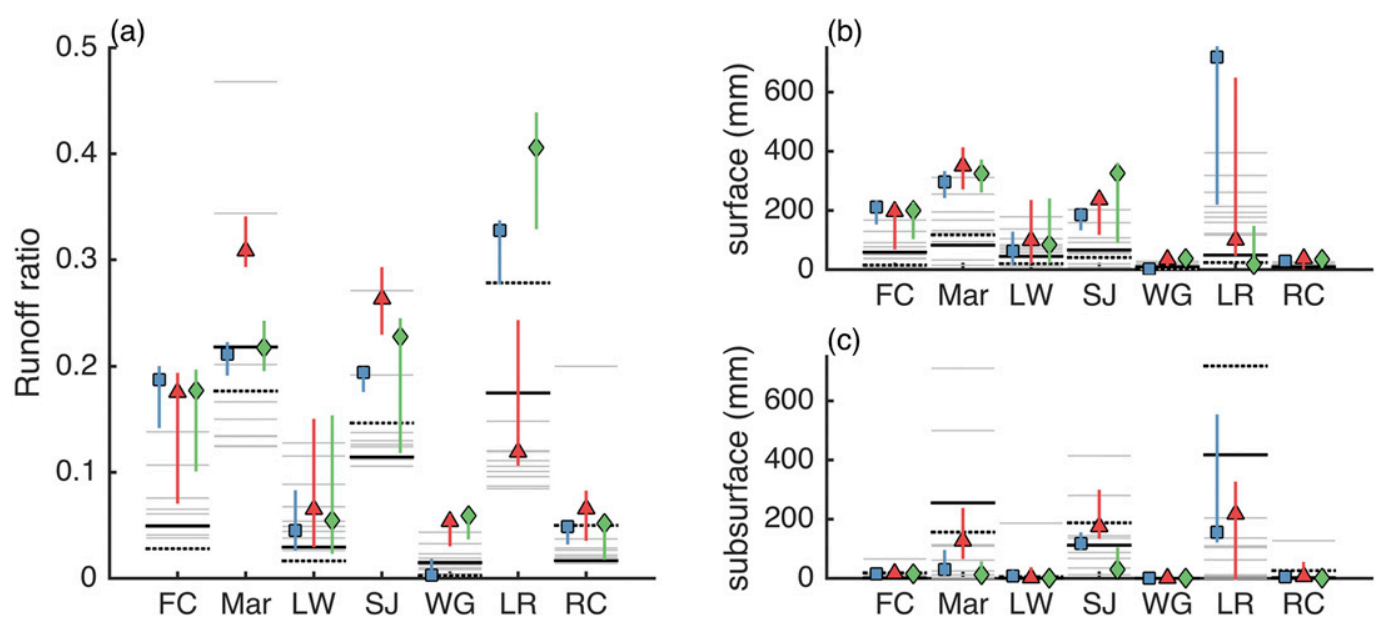

FIG. 8. (a) Runoff ratio at each site for each calibration over 2012-13. Corresponding volume of (b) surface and (c) subsurface runoff. Symbols and lines are as in Fig. 2. Subsurface runoff at LR calibrated to SMOS adj $_{\text {in }}$ off-scale, at $1065 \mathrm{~mm}$. 


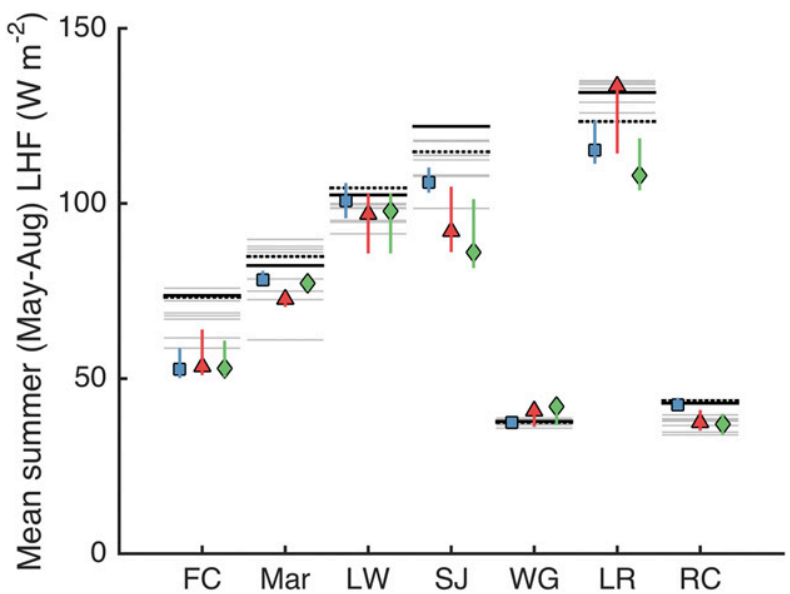

FIG. 9. Mean summertime (May-August) LHF at each site for each calibration and texture-based simulation. Symbols and lines are as in Fig. 2.

addition, the $\theta_{\text {sat }}$ value is clearly an outlier (Fig. 11), and the $b$ value reaches its minimum value.

The mismatch between simulated and observed VSM at LR is too great to be reconciled through parameter calibration. The resulting nonbehavioral simulations reveal the following possibilities: 1) VSM data are not representative of the basin, 2) other parameters or model physics do not adequately characterize this site, and 3) meteorological forcings are inaccurate.

\section{Discussion}

Using the mapped soil texture and the standard SHP lookup table does not yield optimal Noah parameters. Simulations can be improved by changing the site's soil texture designation or by calibrating soil parameters using surface soil moisture from either in situ or SMOS $_{\text {adj }}$ observations. In both cases, RMSD decreases mainly because of improved agreement between the simulated and observed mean surface VSM. Calibrating to SMOS alone does not reliably improve simulations. There are tradeoffs to using calibrated and best texture parameters. It is more likely that total column soil moisture, runoff, and LHF are affected through calibration, possibly yielding nonbehavioral simulations. On the other hand, no texture-based parameter set improves soil moisture dynamics as much as calibrated simulations do. We find this to be especially true at times and locations when the default simulation is worst.

Because of the poor performance of simulations calibrated to SMOS, we limit the remainder of our discussion to parameters and simulations from 1 ) the best in situ and SMOS $_{\text {adj }}$ calibrations and 2) the best texture.
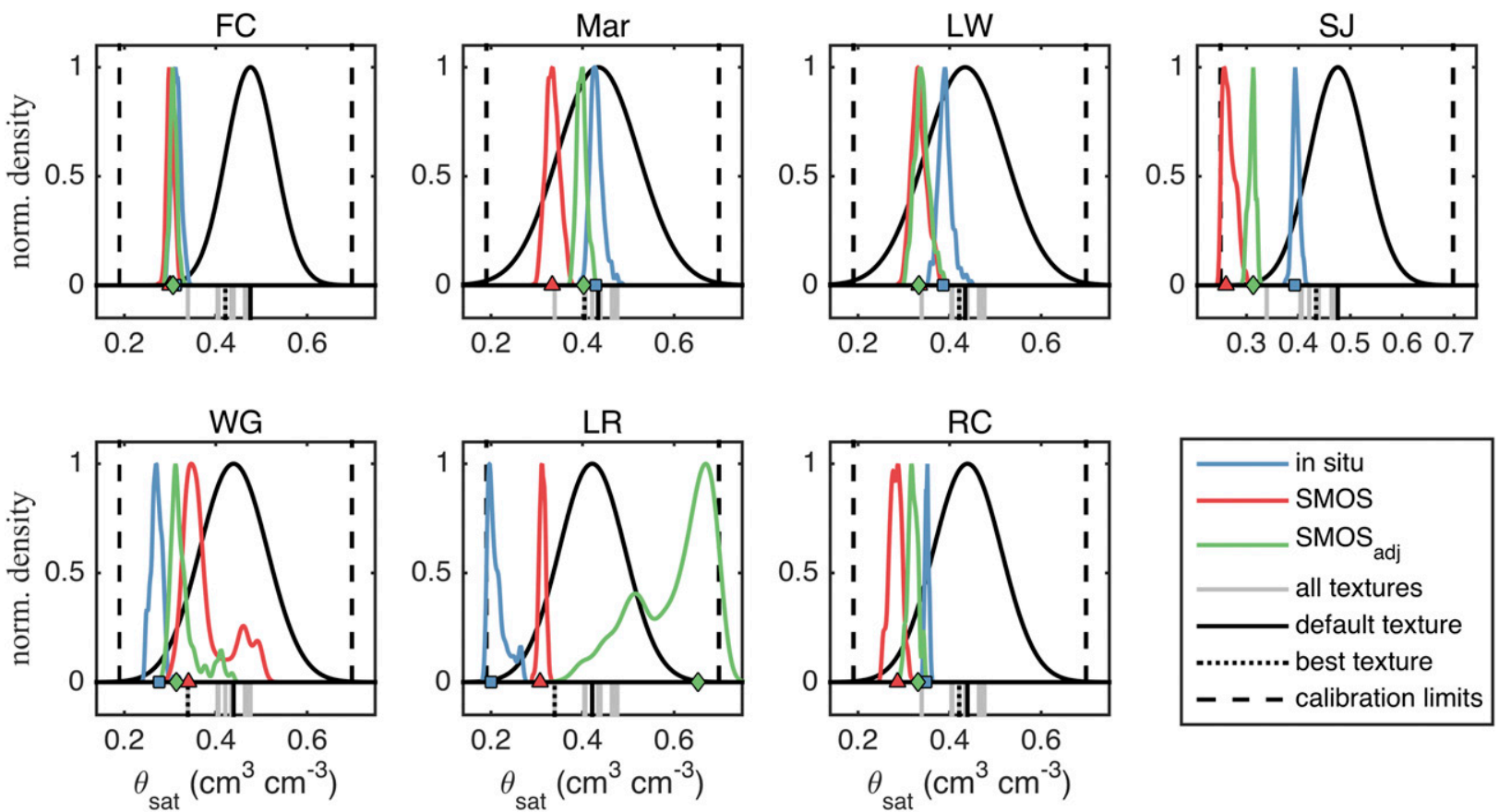

FIG. 10. The distributions of the $\theta_{\text {sat }}$ parameter at each site. Vertical dashed lines indicate the lower and upper constraints placed on the calibration algorithm. Normalized posterior probability density functions at each site for each calibration scheme are shown with colored curves. Laboratory-derived texture-based distributions are shown in black (Cosby et al. 1984). Markers on the $x$ axis show the MAP parameter values for the in situ (blue squares), SMOS (red triangles), and SMOS $_{\text {adj }}$ (green diamonds) calibrations. Along the bottom, gray bars show all texture-based parameter values, black bar shows default parameter value, and dotted bar shows the best texture value. 


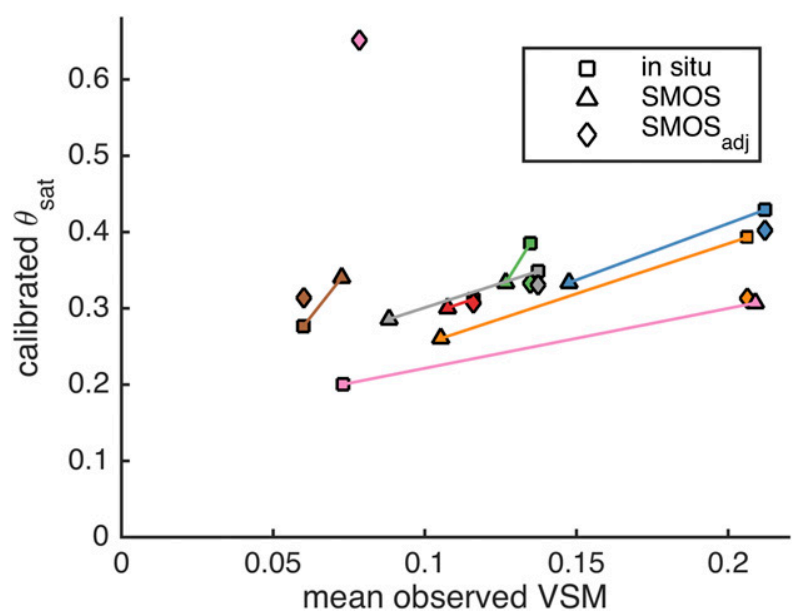

FIG. 11. The calibrated $\theta_{\text {sat }}$ and the mean VSM for in situ (squares), SMOS (triangles), and SMOS tions. Colors indicate site: FC, red; Mar, blue; LW, green; SJ, orange; $\mathrm{WG}$, brown; LR, pink; and $\mathrm{RC}$, gray.

In situ and $\mathrm{SMOS}_{\mathrm{adj}}$-calibrated parameters all have lower $\theta_{\text {sat }}$ and $K_{\text {sat }}$ values than the default simulation does. The effect of decreasing $\theta_{\text {sat }}$ is to lower the threshold for surface runoff, lower the field capacity and residual VSM, and increase the relative conductivity of soil in the column. All three changes decrease the mean modeled surface VSM. The role of lower $K_{\text {sat }}$ values is to decrease the speed at which water can be transferred into and through the soil column. Subsurface runoff decreases, and again, the likelihood of surface runoff increases. These processes explain our experimental results: lower VSM in calibrated simulations. Because water availability is lower, plant transpiration and overall LHF also decrease for all calibrations except $\mathrm{SMOS}_{\text {adj }}$ at WG, where there is limited vegetation. Subsurface runoff is unchanged or lower in all cases except SMOS ${ }_{\text {adj }}$ at LR.
An unfortunate side effect of calibration is the possibility of nonbehavioral simulations. All three calibrated simulations at LR are unreasonable in some way. They provide extreme runoff volumes and parameter values at the edges of their ranges. In addition, the changes to LHF seen at SJ and FC cannot be verified and thus must be considered as potentially problematic. We attribute the LR failures in part to it being wet and well vegetated. Large amounts of precipitation limit the number of soil dry-down events, making SHPs less important relative to meteorological forcings. SMOS retrievals are subject to a wet bias on days with precipitation because of a shortening of the sensing depth (Jackson et al. 2012). Vegetation also increases the chances of inaccurate SMOS retrievals. Poor SMOS performance at LR is not new. In 2010, it had the highest RMSD among LR, WG, LW, and RC (Jackson et al. 2012).

The best texture parameters result in simulations with lower mean surface VSM than default simulations, but they do not change physical processes of the model as much as calibrated parameters do. Surface runoff remains the same. Every site's best texture has lower $b$ and $\psi_{\text {sat }}$ values than its default texture, which decreases the water tension at a given moisture level. Together with higher $K_{\text {sat }}$ values, these three parameters allow faster drainage through the soil column, but the overall volume of subsurface flow does not necessarily change. Because water is still transmitted through the lower layers, LHF is maintained at similar levels to the default simulation.

We have shown important differences in the ability of calibrated and texture-based simulations to capture wetting and drying events. When the default simulation is behaving poorly, all textures suffer from similar problems. Mar, SJ, and RC are the three locations that exhibit high ubRMSDs during some portion of the year.

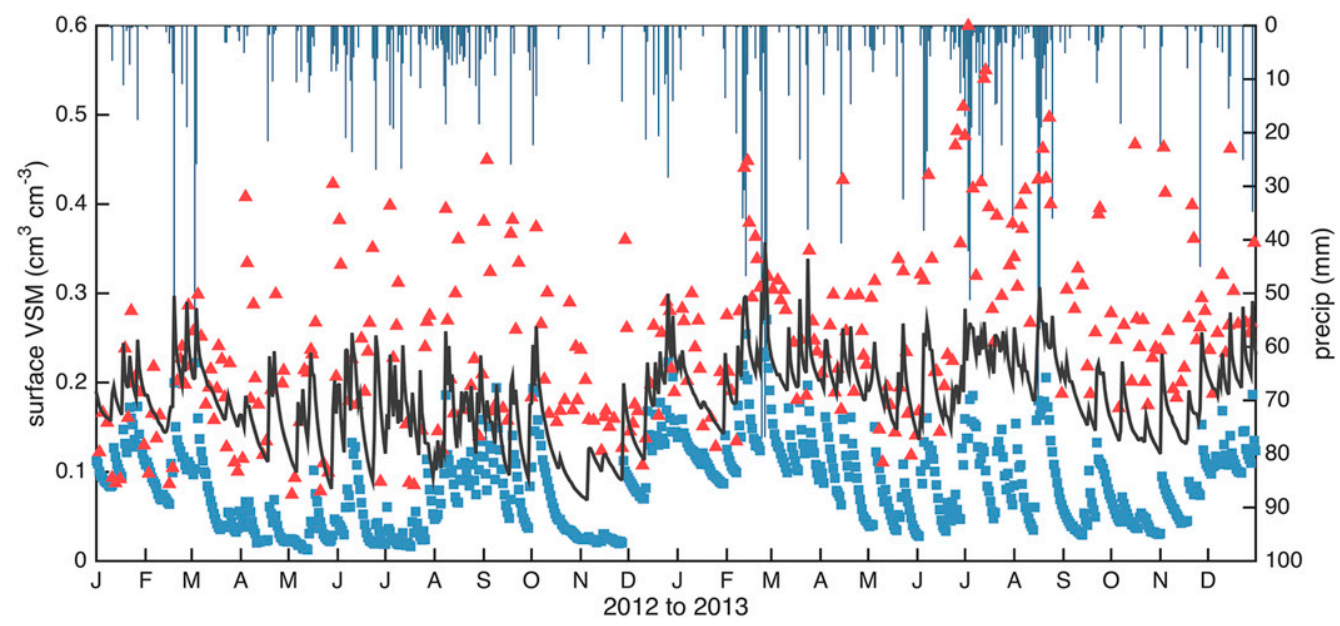

FIG. 12. LR surface soil moisture content of the default simulation (black line), in situ observations (blue squares), and SMOS observations (red triangles). Daily precipitation is also included. 
Visual inspection of the problematic time periods reveals that they occur during successive wetting and drying events. Calibrated simulations show decent agreement with observations. Low $K_{\text {sat }}$ values allow surface soil moisture to increase dramatically during rain events because they limit infiltration to lower layers. Excess rainfall is shed as surface runoff, so subsequent drying is rapid. Texture-based parameters poorly characterize events that dry quickly. They allow for more infiltration, and subsurface runoff and transpiration are by nature slower than surface runoff.

Our study indirectly assesses the effect of scaling on SHPs. Texture-based parameters were developed in small-scale laboratory settings (Cosby et al. 1984). The modeling in this study applies to watersheds on the order of hundreds of square kilometers. By identifying the best texture for each site, we are implicitly identifying the best texture for use at that larger scale. Thus, we reiterate the differences between mapped textures and best textures: $b, \theta_{\text {sat }}$, and $\psi_{\text {sat }}$ decrease and $K_{\text {sat }}$ increases. The change to $b$ causes soils to drain more easily and decreases the residual VSM. The change to $\theta_{\text {sat }}$ causes more runoff, higher relative hydraulic conductivity, and lower overall moisture levels. The changes to $\psi_{\text {sat }}$ and $K_{\text {sat }}$ cause faster infiltration. These processes are consistent with the existence of macropores at larger scales and with the positive relationship between hydraulic conductivity and scale in heterogeneous media (SchulzeMakuch et al. 1999). Although the spatial coverage at Mar is small, its calibrated parameter values were well behaved and not significantly different from those at the other sites.

There are different challenges associated with implementing a calibration strategy or choosing the best texture class at a continental scale. A successful calibration requires high-quality in situ measurements or an unbiased remotely sensed product. At present, neither of these exists outside of specific, well-studied regions. NASA's Soil Moisture Active Passive (SMAP) mission (Entekhabi et al. 2010) may provide data that meet such requirements, but the changes to runoff and LHF discussed here call for a more extensive investigation to assess viability. Alternatively, we can focus on developing a revised soil texture map. Presently, soil maps are associated with actual observations. At our study sites, however, the best texture is different from the mapped texture. We suggest using remotely sensed data to select the best textures at a number of verifiable locations. Then, regionalization techniques could be used to apply the best textures continent-wide (Singh et al. 2012). This will require remotely sensed data of higher quality (smaller or no bias) than we presently have, which we look to SMAP or SMOS reprocessing to provide.

\section{Conclusions}

We summarize our main findings as follows:

1) The mapped soil texture designations used in NLDAS-2 simulations do not provide optimal SHPs for Noah at all sites (FC, Mar, LW, SJ, WG, LR, and RC). Simulations with parameters from a different texture class would match surface soil moisture observations more closely. At SJ and WG, the best textures also improve ubRMSD.

2) Calibration of SHPs is successful when we use in situ or unbiased SMOS observations: the resulting RMSDs between simulated surface soil moisture and in situ observations are lower than those from the default simulations. SMOS observations are not useful for calibration at Mar, SJ, and LR because of bias in the product.

3) Calibration improves the simulation of surface soil moisture dynamics during time periods when default modeled wetting and drying is worst.

4) Little or no change is made to surface soil moisture RMSD or ubRMSD when the default simulations are already good.

5) The best textures and calibrations all produce simulations that have lower mean soil moisture than the default simulations, both at the surface and at depth. The best texture simulations allow for faster drainage through the column, whereas the calibrated simulations produce more surface runoff.

Acknowledgments. This research has been supported by NASA Grant NNX13AF43G. We thank two anonymous reviewers for their helpful comments.

\section{REFERENCES}

Albergel, C., P. de Rosnay, C. Gruhier, J. Muñoz-Sabater, S. Hasenauer, L. Isaksen, Y. Kerr, and W. Wagner, 2012: Evaluation of remotely sensed and modelled soil moisture products using global ground-based in situ observations. Remote Sens. Environ., 118, 215-226, doi:10.1016/ j.rse.2011.11.017.

Al Bitar, A., D. Leroux, Y. H. Kerr, O. Merlin, P. Richaume, A. Sahoo, and E. F. Wood, 2012: Evaluation of SMOS soil moisture products over continental U.S. using the SCAN/ SNOTEL network. IEEE Trans. Geosci. Remote Sens., 50, 1572-1586, doi:10.1109/TGRS.2012.2186581.

Bastidas, L. A., T. S. Hogue, S. Sorooshian, H. V. Gupta, and W. J. Shuttleworth, 2006: Parameter sensitivity analysis for different complexity land surface models using multicriteria methods. J. Geophys. Res., 111, D20101, doi:10.1029/2005JD006377.

Betts, A. K., J. H. Ball, A. C. M. Beljaars, M. J. Miller, and P. A. Viterbo, 1996: The land surface-atmosphere interaction: A review based on observational and global modeling perspectives. J. Geophys. Res., 101, 7209, doi:10.1029/95JD02135. 
Beven, K., 1989: Changing ideas in hydrology-The case of physically-based models. J. Hydrol., 105, 157-172, doi:10.1016/ 0022-1694(89)90101-7.

_ 1995: Linking parameters across scales: Subgrid parameterizations and scale dependent hydrological models. Hydrol. Processes, 9, 507-525, doi:10.1002/hyp.3360090504.

- , and P. Germann, 1982: Macropores and water flow in soils. Water Resour. Res., 18, 1311-1325, doi:10.1029/WR018i005p01311.

— calibration and uncertainty prediction. Hydrol. Processes, 6, 279-298, doi:10.1002/hyp.3360060305.

Blankenship, C., J. Case, B. Zavodsky, and G. Jedlovec, 2014: Assimilation of SMOS retrieved soil moisture into the land information system. EUMETSAT Conf. 2014, Geneva, Switzerland, EUMETSAT, 8 pp. [Available online at http://ntrs.nasa.gov/ archive/nasa/casi.ntrs.nasa.gov/20150001376.pdf.]

Bosch, D. D., V. Lakshmi, T. J. Jackson, M. Choi, and J. M. Jacobs, 2006: Large scale measurements of soil moisture for validation of remotely sensed data: Georgia soil moisture experiment of 2003. J. Hydrol., 323, 120-137, doi:10.1016/j.jhydrol.2005.08.024.

Boyle, D. P., H. V. Gupta, and S. Sorooshian, 2000: Toward improved calibration of hydrologic models: Combining the strengths of manual and automatic methods. Water Resour. Res., 36, 3663-3674, doi:10.1029/2000WR900207.

Burke, E. J., R. J. Gurney, L. P. Simmonds, and T. J. Jackson, 1997: Calibrating a soil water and energy budget model with remotely sensed data to obtain quantitative information about the soil. Water Resour. Res., 33, 1689-1697, doi:10.1029/97WR01000.

$-, \ldots,-$, and P. E. O'Neill, 1998: Using a modeling approach to predict soil hydraulic properties from passive microwave measurements. IEEE Trans. Geosci. Remote Sens., 36, 454-462, doi:10.1109/36.662729.

Campbell, G. S., 1974: Simple method for determining unsaturated conductivity from moisture retention data. Soil Sci., 117, 311314, doi:10.1097/00010694-197406000-00001.

Chen, F., and J. Dudhia, 2001: Coupling an advanced land surfacehydrology model with the Penn State-NCAR MM5 modeling system. Part I: Model implementation and sensitivity. Mon. Wea. Rev., 129, 569-585, doi:10.1175/1520-0493(2001)129<0569: CAALSH $>2.0 . \mathrm{CO} ; 2$.

_ , and Coauthors, 1996: Modeling of land surface evaporation by four schemes and comparison with FIFE observations. J. Geophys. Res., 101, 7251-7268, doi:10.1029/95JD02165.

Colliander, A., and Coauthors, 2015: SMAP L2/L3 soil moisture product validation using in situ based core validation sites. 2015 Fall Meeting, San Francisco, CA, Amer. Geophys. Union, Abstract H43H-1626.

Collow, T. W., A. Robock, J. B. Basara, and B. G. Illston, 2012: Evaluation of SMOS retrievals of soil moisture over the central United States with currently available in situ observations. J. Geophys. Res., 117, D09113, doi:10.1029/2011JD017095.

Cosby, B. J., G. M. Hornberger, R. B. Clapp, and T. R. Ginn, 1984: A statistical exploration of the relationships of soil moisture characteristics to the physical properties of soils. Water Resour. Res., 20, 682-690, doi:10.1029/WR020i006p00682.

Cosh, M. H., T. J. Jackson, P. Starks, and G. Heathman, 2006: Temporal stability of surface soil moisture in the Little Washita River watershed and its applications in satellite soil moisture product validation. J. Hydrol., 323, 168-177, doi:10.1016/j.jhydrol.2005.08.020.

,-- , S. Moran, and R. Bindlish, 2008: Temporal persistence and stability of surface soil moisture in a semi-arid watershed. Remote Sens. Environ., 112, 304-313, doi:10.1016/j.rse.2007.07.001.
, P. J. Starks, J. A. Guzman, and D. N. Moriasi, 2014: Upper Washita River experimental watersheds: Multiyear stability of soil water content profiles. J. Environ. Qual., 43, 1328-1333, doi:10.2134/jeq2013.08.0318.

Crow, W. T., E. F. Wood, and M. Pan, 2003: Multiobjective calibration of land surface model evapotranspiration predictions using streamflow observations and spaceborne surface radiometric temperature retrievals. J. Geophys. Res., 108, 4725, doi:10.1029/2002JD003292.

— D. G. Miralles, and M. H. Cosh, 2010: A quasi-global evaluation system for satellite-based surface soil moisture retrievals. IEEE Trans. Geosci. Remote Sens., 48, 2516-2527, doi:10.1109/TGRS.2010.2040481.

Doherty, J., and D. Welter, 2010: A short exploration of structural noise. Water Resour. Res., 46, W05525, doi:10.1029/ 2009WR008377.

Duan, Q., S. Sorooshian, and V. Gupta, 1992: Effective and efficient global optimization for conceptual rainfall-runoff models. Water Resour. Res., 28, 1015-1031, doi:10.1029/ 91WR02985.

Ek, M. B., K. E. Mitchell, Y. Lin, E. Rogers, P. Grunmann, V. Koren, G. Gayno, and J. D. Tarpley, 2003: Implementation of Noah land surface model advances in the National Centers for Environmental Prediction operational mesoscale Eta model. J. Geophys. Res., 108, 8851, doi:10.1029/2002JD003296.

Entekhabi, D., I. Rodriguez-Iturbe, and F. Castelli, 1996: Mutual interaction of soil moisture state and atmospheric processes. J. Hydrol., 184, 3-17, doi:10.1016/0022-1694(95)02965-6.

— (SMAP) mission. Proc. IEEE, 98, 704-716, doi:10.1109/ JPROC.2010.2043918.

Famiglietti, J. S., D. Ryu, A. A. Berg, M. Rodell, and T. J. Jackson, 2008: Field observations of soil moisture variability across scales. Water Resour. Res., 44, W01423, doi:10.1029/ 2006WR005804.

Franks, S. W., and K. J. Beven, 1997: Bayesian estimation of uncertainty in land surface-atmosphere flux predictions. J. Geophys. Res., 102, 23 991-23 999, doi:10.1029/97JD02011.

Gelman, A., and D. B. Rubin, 1992: Inference from iterative simulation using multiple sequences. Stat. Sci., 7, 457-472, doi:10.1214/ss/1177011136.

Grayson, R. B., and G. Blöschl, Eds., 2000: Spatial Patterns in Catchment Hydrology. Cambridge University Press, 416 pp.

Guillod, B. P., E. L. Davin, C. Kündig, G. Smiatek, and S. I. Seneviratne, 2013: Impact of soil map specifications for European climate simulations. Climate Dyn., 40, 123-141, doi:10.1007/s00382-012-1395-z.

Gupta, H. V., S. Sorooshian, and P. O. Yapo, 1998: Toward improved calibration of hydrologic models: Multiple and noncommensurable measures of information. Water Resour. Res., 34, 751-763, doi:10.1029/97WR03495.

_ L. A. Bastidas, S. Sorooshian, W. J. Shuttleworth, and Z. L. Yang, 1999: Parameter estimation of a land surface scheme using multicriteria methods. J. Geophys. Res., 104, 1949119503, doi:10.1029/1999JD900154.

Gutmann, E. D., and E. E. Small, 2005: The effect of soil hydraulic properties vs. soil texture in land surface models. Geophys. Res. Lett., 32, L02402, doi:10.1029/2004GL021843.

$\longrightarrow$, and - 2007: A comparison of land surface model soil hydraulic properties estimated by inverse modeling and pedotransfer functions. Water Resour. Res., 43, W05418, doi:10.1029/ 2006WR005135. 
— , and - 2010: A method for the determination of the hydraulic properties of soil from MODIS surface temperature for use in land-surface models. Water Resour. Res., 46, W06520, doi:10.1029/2009WR008203.

Hansen, M., R. DeFries, J. R. G. Townshend, and R. Sohlberg, 2000: Global land cover classification at $1 \mathrm{~km}$ spatial resolution using a classification tree approach. Int. J. Remote Sens., 21, 1331-1364, doi:10.1080/014311600210209.

Harrison, K. W., S. V. Kumar, C. D. Peters-Lidard, and J. A. Santanello, 2012: Quantifying the change in soil moisture modeling uncertainty from remote sensing observations using Bayesian inference techniques. Water Resour. Res., 48, W11514, doi:10.1029/2012WR012337.

Harter, T., and J. W. Hopmans, 2004: Role of vadose-zone flow processes in regional-scale hydrology: review, opportunities, and challenges. Unsaturated-Zone Modeling: Progress, Challenges and Applications, R. A. Feddes, G. H. De Rooij, and J. C. Van Dam, Eds., Kluwer Academic Publishers, 179-208.

Hogue, T. S., L. Bastidas, H. Gupta, S. Sorooshian, K. Mitchell, and W. Emmerich, 2005: Evaluation and transferability of the Noah land surface model in semiarid environments. J. Hydrometeor., 6, 68-84, doi:10.1175/JHM-402.1.

$-, \ldots, \ldots$, and,- 2006 : Evaluating model performance and parameter behavior for varying levels of land surface model complexity. Water Resour. Res., 42, W08430, doi:10.1029/2005WR004440.

Holtan, H. N., C. B. England, G. P. Lawless, and G. A. Schumaker, 1968: Moisture-tension data for selected soils on experimenta watersheds. Rep. ARS 41-144, Agriculture Research Service, USDA, $609 \mathrm{pp}$

Hossain, F., and E. N. Anagnostou, 2005: Numerical investigation of the impact of uncertainties in satellite rainfall estimation and land surface model parameters on simulation of soil moisture. Adv. Water Resour., 28, 1336-1350, doi:10.1016/ j.advwatres.2005.03.013.

Houser, P. R., H. V. Gupta, W. J. Shuttleworth, and J. S. Famiglietti, 2001: Multiobjective calibration and sensitivity of a distributed land surface water and energy balance model. J. Geophys. Res. 106, 33 421-33 433, doi:10.1029/2000JD900803.

Ines, A. V. M., and B. P. Mohanty, 2009: Near-surface soil moisture assimilation for quantifying effective soil hydraulic properties using genetic algorithms: 2. Using airborne remote sensing during SGP97 and SMEX02. Water Resour. Res., 45, W01408, doi:10.1029/2008WR007022.

Jackson, T. J., 1980: Profile soil moisture from surface measurements. J. Irrig. Drain. Div., 106, 81-92.

— system for soil moisture: Some supporting research. IEEE Trans. Geosci. Remote Sens., 27, 225-235, doi:10.1109/36.20301. , and Coauthors, 2010: Validation of Advanced Microwave Scanning Radiometer soil moisture products. IEEE Trans. Geosci. Remote Sens., 48, 4256-4272, doi:10.1109/TGRS.2010.2051035.

— Salinity (SMOS) soil moisture over watershed networks in the U.S. IEEE Trans. Geosci. Remote Sens., 50, 1530-1543, doi:10.1109/TGRS.2011.2168533.

Juglea, S., and Coauthors, 2010: Modelling soil moisture at SMOS scale by use of a SVAT model over the Valencia Anchor Station. Hydrol. Earth Syst. Sci., 14, 831-846, doi:10.5194/ hess-14-831-2010.

Kerr, Y. H., and Coauthors, 2010a: The SMOS mission: New tool for monitoring key elements of the global water cycle. Proc IEEE, 98, 666-687, doi:10.1109/JPROC.2010.2043032.
- P. Waldteufel, P. Richaume, I. Davenport, P. Ferrazoli, and J.-P. Wigneron, 2010b: SMOS level 2 processor for soil moisture. Algorithm Theoretical Basis Doc. SO-TN-ESL-SMGS-001, CESBIO, 123 pp. [Available online at http://www.cesbio. ups-tlse.fr/data_all/SMOS-doc/atbd/SMOS_SM_ATBD_final.pdf.]

Koren, V., F. Moreda, and M. Smith, 2008: Use of soil moisture observations to improve parameter consistency in watershed calibration. Phys. Chem. Earth, 33, 1068-1080, doi:10.1016/ j.pce.2008.01.003.

Kurc, S. A., and E. E. Small, 2004: Dynamics of evapotranspiration in semiarid grassland and shrubland ecosystems during the summer monsoon season, central New Mexico. Water Resour. Res., 40, W09305, doi:10.1029/2004WR003068.

Liang, X., J. Guo, and L. R. Leung, 2004: Assessment of the effects of spatial resolutions on daily water flux simulations. $J$. Hydrol., 298, 287-310, doi:10.1016/j.jhydrol.2003.07.007.

Liu, Y., H. V. Gupta, S. Sorooshian, L. A. Bastidas, and W. J. Shuttleworth, 2005: Constraining land surface and atmospheric parameters of a locally coupled model using observational data. J. Hydrometeor., 6, 156-172, doi:10.1175/ JHM407.1.

Mattikalli, N. M., E. T. Engman, L. R. Ahuja, and T. J. Jackson, 1998: Microwave remote sensing of soil moisture for estimation of profile soil property. Int. J. Remote Sens., 19, 17511767, doi:10.1080/014311698215234.

Miller, D. A., and R. A. White, 1998: A conterminous United States multilayer soil characteristics dataset for regional climate and hydrology modeling. Earth Interact., 2, 1-26, doi:10.1175/ 1087-3562(1998)002<0001:ACUSMS>2.3.CO;2.

Milzow, C., P. E. Krogh, and P. Bauer-Gottwein, 2011: Combining satellite radar altimetry, SAR surface soil moisture and GRACE total storage changes for hydrological model calibration in a large poorly gauged catchment. Hydrol. Earth Syst. Sci., 15, 1729-1743, doi:10.5194/hess-15-1729-2011.

Mitchell, K. E., and Coauthors, 2004: The multi-institution North American Land Data Assimilation System (NLDAS): Utilizing multiple GCIP products and partners in a continental distributed hydrological modeling system. J. Geophys. Res., 109, D07S90, doi:10.1029/2003JD003823.

Nandagiri, L., 2007: Calibrating hydrological models in ungauged basins: Possible use of areal evapotranspiration instead of streamflows. IAHS Publ., 309, 275-281. [Available online at http://iahs.info/uploads/dms/309032.pdf.]

Osborne, T. M., D. M. Lawrence, J. M. Slingo, A. J. Challinor, and T. R. Wheeler, 2004: Influence of vegetation on the local climate and hydrology in the tropics: Sensitivity to soil parameters. Climate Dyn., 23, 45-61, doi:10.1007/s00382-004-0421-1.

Pan, M., A. K. Sahoo, E. F. Wood, A. Al Bitar, D. Leroux, and Y. H. Kerr, 2012: An initial assessment of SMOS derived soil moisture over the continental United States. IEEE J. Sel. Top. Appl. Earth Obs. Remote Sens., 5, 1448-1457, doi:10.1109/ JSTARS.2012.2194477.

Pauwels, V. R. N., A. Balenzano, G. Satalino, H. Skriver, N. E. C. Verhoest, and F. Mattia, 2009: Optimization of soil hydraulic model parameters using synthetic aperture radar data: An integrated multidisciplinary approach. IEEE Trans. Geosci. Remote Sens., 47, 455-467, doi:10.1109/TGRS.2008.2007849.

Peters-Lidard, C. D., D. M. Mocko, M. Garcia, J. A. Santanello, M. A. Tischler, M. S. Moran, and Y. Wu, 2008: Role of precipitation uncertainty in the estimation of hydrologic soil properties using remotely sensed soil moisture in a semiarid environment. Water Resour. Res., 44, W05S18, doi:10.1029/ 2007WR005884. 
Pitman, A. J., 2003: The evolution of, and revolution in, land surface schemes designed for climate models. Int. J. Climatol., 23, 479-510, doi:10.1002/joc.893.

Rawls, W. J., P. Yates, and L. Asmussen, 1976: Calibration of selected infiltration equations for the Georgia Coastal Plain. Rep. ARS-S-113, Agriculture Research Service, USDA, 110 pp.

Reichle, R. H., and R. D. Koster, 2004: Bias reduction in short records of satellite soil moisture. Geophys. Res. Lett., 31, L19501, doi:10.1029/2004GL020938.

Richards, L. A., 1931: Capillary conduction of liquids through porous mediums. J. Appl. Phys., 1, 318-333, doi:10.1063/ 1.1745010 .

Richter, H., A. W. Western, and F. H. S. Chiew, 2004: The effect of soil and vegetation parameters in the ECMWF land surface scheme. J. Hydrometeor., 5, 1131-1146, doi:10.1175/JHM-362.1.

Rosero, E., Z.-L. Yang, T. Wagener, L. E. Gulden, S. Yatheendradas, and G.-Y. Niu, 2010: Quantifying parameter sensitivity, interaction, and transferability in hydrologically enhanced versions of the Noah land surface model over transition zones during the warm season. J. Geophys. Res., 115, D03106, doi:10.1029/ 2009JD012035.

Salvucci, G. D., and D. Entekhabi, 2011: An alternate and robust approach to calibration for the estimation of land surface model parameters based on remotely sensed observations. Geophys. Res. Lett., 38, L16404, doi:10.1029/2011GL048366.

Santanello, J. A., C. D. Peters-Lidard, M. E. Garcia, D. M. Mocko, M. A. Tischler, M. S. Moran, and D. P. Thoma, 2007: Using remotely-sensed estimates of soil moisture to infer soil texture and hydraulic properties across a semi-arid watershed. Remote Sens. Environ., 110, 79-97, doi:10.1016/j.rse.2007.02.007.

Schaap, M. G., and F. J. Leij, 1998: Database-related accuracy and uncertainty of pedotransfer functions. Soil Sci., 163, 765-779, doi:10.1097/00010694-199810000-00001.

Schär, C., D. Lüthi, U. Beyerle, and E. Heise, 1999: The soilprecipitation feedback: A process study with a regional climate model. J. Climate, 12, 722-741, doi:10.1175/ 1520-0442(1999)012<0722:TSPFAP $>2.0 . \mathrm{CO} ; 2$.

Schulze-Makuch, D., D. A. Carlson, D. S. Cherkauer, and P. Malik, 1999: Scale dependency of hydraulic conductivity in heterogeneous media. Ground Water, 37, 904-919, doi:10.1111/ j.1745-6584.1999.tb01190.x.

Singh, S. K., A. Bárdossy, J. Götzinger, and K. P. Sudheer, 2012: Effect of spatial resolution on regionalization of hydrological model parameters. Hydrol. Processes, 26, 3499-3509, doi:10.1002/ hyp.8424.

Skamarock, W. C., and Coauthors, 2008: A description of the Advanced Research WRF version 3. NCAR Tech. Note NCAR/TN-475+STR, 113 pp., doi:10.5065/D68S4MVH.

Soet, M., and J. N. M. Stricker, 2003: Functional behaviour of pedotransfer functions in soil water flow simulation. Hydrol. Processes, 17, 1659-1670, doi:10.1002/hyp.1207.

Sorooshian, S., Q. Duan, and V. K. Gupta, 1993: Calibration of rainfall-runoff models: Application of global optimization to the Sacramento Soil Moisture Accounting Model. Water Resour. Res., 29, 1185-1194, doi:10.1029/92WR02617.

Teuling, A. J., R. Uijlenhoet, B. van den Hurk, and S. I. Seneviratne, 2009: Parameter sensitivity in LSMs: An analysis using stochastic soil moisture models and ELDAS soil parameters. J. Hydrometeor., 10, 751-765, doi:10.1175/2008JHM1033.1.

Troy, T. J., E. F. Wood, and J. Sheffield, 2008: An efficient calibration method for continental-scale land surface modeling. Water Resour. Res., 44, W09411, doi:10.1029/2007WR006513.

Vereecken, H., R. Kasteel, J. Vanderborght, and T. Harter, 2007: Upscaling hydraulic properties and soil water flow processes in heterogeneous soils. Vadose Zone J., 6, 1-28, doi:10.2136/ vzj2006.0055.

Vrugt, J. A., H. V. Gupta, W. Bouten, and S. Sorooshian, 2003: A Shuffled Complex Evolution Metropolis algorithm for optimization and uncertainty assessment of hydrologic model parameters. Water Resour. Res., 39, 1201, doi:10.1029/ 2002WR001642.

— C. J. F. ter Braak, M. P. Clark, J. M. Hyman, and B. A. Robinson, 2008: Treatment of input uncertainty in hydrologic modeling: Doing hydrology backward with Markov chain Monte Carlo simulation. Water Resour. Res., 44, W00B09, doi:10.1029/2007WR006720.

_ B. A. Robinson, and J. M. Hyman, 2009: Self-adaptive multimethod search for global optimization in real-parameter spaces. IEEE Trans. Evol. Comput., 13, 243-259, doi:10.1109/ TEVC.2008.924428.

Wöhling, T., and Coauthors, 2013: Multiresponse, multiobjective calibration as a diagnostic tool to compare accuracy and structural limitations of five coupled soil-plant models and CLM3.5. Water Resour. Res., 49, 8200-8221, doi:10.1002/2013WR014536.

Wooldridge, S., J. Kalma, and J. Walker, 2003: Importance of soil moisture measurements for inferring parameters in hydrologic models of low-yielding ephemeral catchments. Environ. Modell. Software, 18, 35-48, doi:10.1016/S1364-8152(02)00038-5.

Wösten, J. H. M., P. A. Finke, and M. J. W. Jansen, 1995: Comparison of class and continuous pedotransfer functions to generate soil hydraulic characteristics. Geoderma, 66, 227237, doi:10.1016/0016-7061(94)00079-P.

Xia, Y., and Coauthors, 2012: Continental-scale water and energy flux analysis and validation for the North American Land Data Assimilation System project phase 2 (NLDAS-2): 1. Intercomparison and application of model products. J. Geophys. Res., 117, D03109, doi:10.1029/2011JD016048.

—, M. B. Ek, Y. Wu, T. W. Ford, and S. M. Quiring, 2015: Comparison of NLDAS-2 simulated and NASMD observed daily soil moisture. Part II: Impact of soil texture classification and vegetation type mismatches. J. Hydrometeor., 16, 19812000, doi:10.1175/JHM-D-14-0097.1.

Yapo, P. O., H. V. Gupta, and S. Sorooshian, 1996: Automatic calibration of conceptual rainfall-runoff models: Sensitivity to calibration data. J. Hydrol., 181, 23-48, doi:10.1016/ 0022-1694(95)02918-4. 